\title{
Associations of sleep disturbance with ADHD: implications for treatment
}

\author{
Allan Hvolby \\ Received: 9 April 2014/ Accepted: 8 July 2014/Published online: 17 August 2014 \\ (C) The Author(s) 2014. This article is published with open access at Springerlink.com
}

\begin{abstract}
Attention-deficit/hyperactivity disorder (ADHD) is commonly associated with disordered or disturbed sleep. The relationships of ADHD with sleep problems, psychiatric comorbidities and medications are complex and multidirectional. Evidence from published studies comparing sleep in individuals with ADHD with typically developing controls is most concordant for associations of ADHD with: hypopnea/apnea and peripheral limb movements in sleep or nocturnal motricity in polysomnographic studies; increased sleep onset latency and shorter sleep time in actigraphic studies; and bedtime resistance, difficulty with morning awakenings, sleep onset difficulties, sleep-disordered breathing, night awakenings and daytime sleepiness in subjective studies. ADHD is also frequently coincident with sleep disorders (obstructive sleep apnea, peripheral limb movement disorder, restless legs syndrome and circadian-rhythm sleep disorders). Psychostimulant medications are associated with disrupted or disturbed sleep, but also 'paradoxically' calm some patients with ADHD for sleep by alleviating their symptoms. Long-acting formulations may have insufficient duration of action, leading to symptom rebound at bedtime. Current guidelines recommend assessment of sleep disturbance during evaluation of ADHD, and before initiation of pharmacotherapy, with healthy sleep practices the firstline option for addressing sleep problems. This review aims to provide a comprehensive overview of the relationships between ADHD and sleep, and presents a conceptual model of the modes of interaction: ADHD may cause sleep problems as an intrinsic feature of the disorder; sleep
\end{abstract}

\footnotetext{
A. Hvolby $(\bowtie)$

Department of Child and Adolescent Psychiatry, Psychiatry of Southern Denmark, Gl. Vardevej 101, 6715 Esbjerg N, Denmark e-mail: allan.hvolby@rsyd.dk
}

problems may cause or mimic ADHD; ADHD and sleep problems may interact, with reciprocal causation and possible involvement of comorbidity; and ADHD and sleep problems may share a common underlying neurological etiology.

Keywords Sleep · ADHD - Stimulant · Amfetamine . Methylphenidate $\cdot$ Atomoxetine

\section{Introduction}

Attention-deficit/hyperactivity disorder (ADHD) is a common neurodevelopmental disorder that has been estimated to affect approximately $5.3 \%$ of children and adolescents worldwide (Polanczyk et al. 2007) and to persist into adulthood in approximately two-thirds of patients (Spencer et al. 1998; Wender 1998). Inattention, hyperactivity and impulsiveness are recognized as the symptoms of ADHD according to the current diagnostic criteria [Diagnostic and Statistical Manual of Mental Disorders (DSM), Fifth Edition (American Psychiatric Association 2013; Casas et al. 2013) and International Classification of Diseases and Related Health Problems, 10th Revision (ICD10) (World Health Organization 1992)] and are associated with characteristic behavioral difficulties and impairments of day-to-day functioning. Although diagnosis relies on observations made while patients are awake, the prevalence of sleep disturbances in individuals with ADHD is reported to be in the range 25-55\% (Corkum et al. 1998; Hodgkins et al. 2013; Owens 2005; Sung et al. 2008). In a recent Australian study, $62 \%$ of children with ADHD had moderate or severe sleep problems and $22 \%$ took sleep medications during the 1-week observation period (Efron et al. 2014). Indeed, high nocturnal activity and disordered sleep 
were defining characteristics of 'hyperkinetic reaction in childhood' or 'attention deficit disorder' in earlier versions of the DSM (American Psychiatric Association 1980; Barkley 1990; Sadeh et al. 2006; Spruyt and Gozal 2011).

The association of sleep with ADHD is multifaceted and complex. Problems with sleep may be an intrinsic feature of ADHD, or may both exacerbate and be exacerbated by the symptoms of the disorder. Problems with sleep can, however, also lead to the development of ADHD or ADHD-like symptoms, potentially resulting in misdiagnosis (Cortese et al. 2006b; Owens 2008). The effects of restricted, disordered or disturbed sleep can manifest as symptoms, behaviors or functional impairments that are remarkably similar to those of ADHD (Beebe 2006; Gruber 2009; O'Brien 2009). The interrelationships are further complicated by the use of psychostimulant medications to treat ADHD, which impair sleep in some patients (Spruyt and Gozal 2011) but paradoxically (Bradley 1937) improve sleep in others via a calming effect (Jerome 2001; Kinsbourne 1973; Kooij et al. 2001; Kratochvil et al. 2005). For these reasons, it has been recommended that primary sleep disorders should be ruled out before initiating ADHD medication (Cortese et al. 2013a; Lecendreux and Cortese 2007). Behavioral interventions targeted at improving sleep may benefit some patients (Cortese et al. 2013a) and should form part of the multimodal ADHD management plan recommended for patients receiving pharmacotherapy (Graham et al. 2011; Lecendreux and Cortese 2007; Wolraich et al. 2011).

Psychiatric comorbidities are common in children with ADHD: up to $87 \%$ of children with an ADHD diagnosis have at least one comorbidity, and $20 \%$ have three or more comorbid conditions (Hodgkins et al. 2013; Rowland et al. 2002; Spruyt and Gozal 2011). Psychiatric illnesses such as bipolar disorder, autism, post-traumatic stress disorder and obsessive compulsive disorder often occur coincidently with ADHD, and are also associated with sleep problems, which may both result from and exacerbate comorbid psychiatric symptoms (Ivanenko et al. 2004). Problems with sleep are likely to have adverse effects on healthrelated quality of life for children with ADHD and their families (Hvolby et al. 2008; Saxby and Morgan 1993) and may also contribute to the development of comorbid anxiety, depression or oppositional defiant disorder (Breslau et al. 1996; Hvolby et al. 2008; Mick et al. 2000). The interactions of comorbid disorders and associated medications with ADHD and sleep disturbances are therefore important to consider when managing patients.

The complex, multidirectional interactions of sleep with ADHD, medication and psychiatric comorbidities remain unclear despite extensive research. The reciprocal nature of the relationships between ADHD and sleep may reflect the functional and neuroanatomical overlap between brain regions involved in attention, arousal and sleep regulation (Owens et al. 2013; Owens 2008). This review provides a broad but comprehensive overview of the relationships between ADHD and sleep, with the aims of fostering greater understanding of the sleep-related issues faced by many individuals with ADHD and of informing the pharmacological and non-pharmacological management of the disorder. In support of these aims, this article presents a conceptual model of the potential interactions of sleep with ADHD which is intended as an aid in the interpretation of evidence related to the interactions of sleep problems with ADHD and with medications used to treat ADHD.

\section{Measuring sleep in patients with ADHD}

Objective measures (polysomnography, actigraphy and the multiple sleep latency test [MSLT]) and subjective measures (e.g., parent- or self-rated questionnaires and diaries) are used to assess sleep in patients with ADHD.

\section{Polysomnography}

Polysomnography involves simultaneous and continuous measurement of multiple physiological parameters, and is usually conducted in a sleep laboratory. A combination of electroencephalography, electrocardiography, electromyography, electrooculography, pneumography and pulse oximetry is typical, sometimes together with audiovisual recordings.

Polysomnography is considered the 'gold standard' for the objective measurement of sleep (Cortese et al. 2009; Owens 2008), but is subject to a number of limitations. Children's sleep patterns may be affected by the unfamiliar environment of the sleep laboratory or by the recording apparatus (Beebe 2011; Bessey et al. 2013). At least some polysomnographic parameters are subject to 'first-night effects,' whereby sleep characteristics on a single night may differ from those recorded on subsequent nights (Katz et al. 2002; Kirov et al. 2012; Lorenzo and Barbanoj 2002; Sadeh et al. 2006; Scholle et al. 2003).

Three published meta-analyses of polysomnographic studies have investigated sleep in children with ADHD and typically developing controls (Cortese et al. 2006a, 2009; Sadeh et al. 2006). In a meta-analysis of 11 studies, the only statistically significant polysomnographic finding was a higher incidence of periodic limb movements in sleep (PLMS) in children with ADHD than in controls (Sadeh et al. 2006). A subsequent meta-analysis of studies in non-medicated patients included 5 of these 11 studies and 4 additional polysomnographic studies (Cortese et al. 2009), and updated a previous analysis by the same group (Cortese et al. 2006a). Statistically significant polysomnographic findings were 
lower sleep efficiency, higher apnea-hypopnea index (AHI) and a larger number of sleep stage shifts per hour in children with ADHD than in controls (Cortese et al. 2009). Data on limb movements could not be pooled in this meta-analysis, but the authors noted that the included studies were consistent in describing elevations in indices of PLMS or general sleep movements in children with ADHD compared with controls (Cortese et al. 2006a, 2009). Since publication of these meta-analyses, four individual polysomnographic studies in un-medicated children with ADHD versus controls have each reported no statistically significant differences in any polysomnographic index, including PLMS, AHI and sleep efficiency (Choi et al. 2010; Gruber et al. 2012a; Prihodova et al. 2010, 2012), and one study has reported statistically significant differences in almost all of the polysomnographic parameters assessed (Silvestri et al. 2009). This study also indicated that children with hyperactive symptoms had a higher mean PLMS index than those with predominantly inattentive ADHD (Silvestri et al. 2009). Polysomnographic data in adults with ADHD are scarce (Yoon et al. 2012), with one study reporting no significant differences (Philipsen et al. 2005) and one reporting significant differences in four indices, compared with controls (Sobanski et al. 2008).

Several studies have reported changes in rapid eye movement (REM) sleep in children and adolescents with ADHD (Golan et al. 2004; Gruber et al. 2009; Kirov et al. 2004; O'Brien et al. 2003a, b). Inter-study inconsistencies in whether REM sleep is increased or decreased in patients with ADHD compared with controls have been ascribed to changes in REM sleep during maturation (Kirov and Brand 2014). However, three meta-analyses of polysomnographic studies found no significant alterations in REM sleep parameters in children with ADHD compared with controls (Cortese et al. 2006a, 2009; Sadeh et al. 2006). The most recent and inclusive of these ruled out inter-study heterogeneity as being responsible for the lack of any detectable pooled difference in REM sleep parameters (Cortese et al. 2009).

In summary, the available evidence from polysomnographic studies is most concordant for associations of ADHD with apnea/hypopnea and PLMS/nocturnal motor activity in children (Cortese et al. 2006a; Spruyt and Gozal 2011). The number of studies is limited, and some parameters have been reported in only one or two studies, indicating a need for additional research (Cortese et al. 2009). For example, two studies of sleep microstructure (the cyclic alternating pattern) in patients with ADHD have yielded inconsistent results (Miano et al. 2006; Prihodova et al. 2012). Furthermore, current polysomnographic indices may not be sensitive enough to detect subtle patterns of sleep fragmentation (Owens et al. 2013; Yoon et al. 2012). For example, episodes of PLMS in children with ADHD are reportedly characterized by atypical, low periodicity movements which may not register on all polysomnographic indices of PLMS, yet these may be more likely than highly periodic, stereotypical PLMS to be associated with arousal and sleep disturbance (Ferri et al. 2013).

Polysomnographic studies are generally small (typically 20-30 participants per arm), and there is a need for largerscale, multicenter studies (Cortese et al. 2009; Sadeh et al. 2006). Sleep parameters in children with ADHD are influenced by age, gender, comorbidities, ADHD diagnostic criteria and subtype, and the inclusion of an adaptation night (to compensate for first-night effects), but these variables are not controlled in many studies (Sadeh et al. 2006). In particular, the different diagnostic criteria used in different studies may be an important factor underlying the inconsistency of polysomnographic findings across studies (Gomes et al. 2013; Kirov and Brand 2014; Kirov et al. 2004). Furthermore, children with ADHD often show marked intra-individual variability and instability in sleep parameters, rather than a consistent level of impairment (Gruber and Sadeh 2004; Gruber et al. 2000; Hvolby et al. 2008; Lecendreux and Cortese 2007; Lecendreux et al. 2000; Moreau et al. 2013; Prihodova et al. 2010).

\section{Actigraphy}

Actigraphy involves wearing a sensor, usually on the wrist, to measure motor activity. Current devices are small, lightweight, unobtrusive and convenient. Despite the increasing use of actigraphy in pediatric studies, variations remain in the device used, the point of attachment, the parameters measured and the method for storing and analyzing the signals (Meltzer et al. 2012). Actigraphy is unable to provide information on sleep architecture, PLMS, snoring or apnea/hypopnea. Compared with polysomnography, actigraphy may overestimate waking after sleep onset and underestimate total sleep time, and may also underestimate sleep onset latency (presumably because immobility generally precedes sleep) (Spruyt et al. 2011). Nevertheless, actigraphy has the unique advantage of providing a non-invasive means of measuring sleep-wake patterns objectively over extended periods of time under everyday conditions.

A meta-analysis of four actigraphic studies reported statistically significantly longer mean sleep onset latency and shorter true sleep time in non-medicated children with ADHD than in typically developing controls (Cortese et al. 2009). Figure 1 illustrates data from one of these studies and shows that mean actigraphic sleep onset latency was longer in children with ADHD than in community controls and children with other psychiatric conditions (Hvolby et al. 2008). Mean longest sleep latency was also highest in children with ADHD, but total sleep time did not significantly differ among the three groups (Hvolby et al. 2008). 


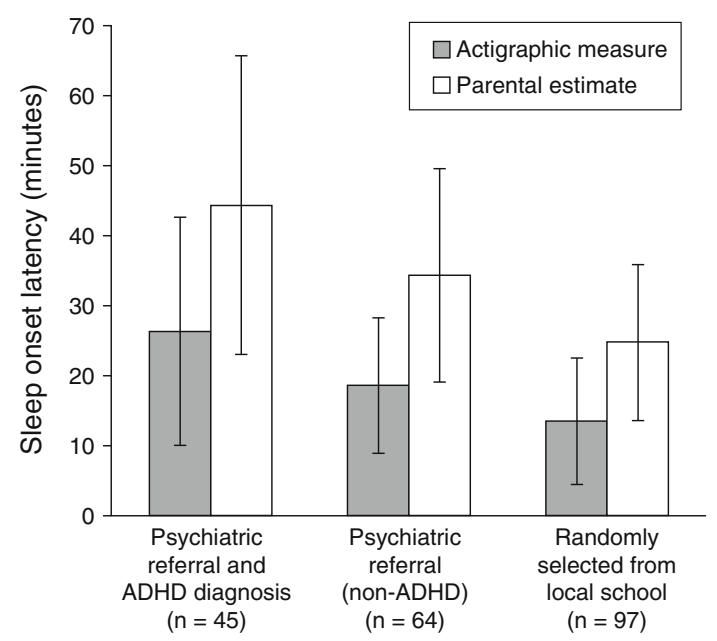

Fig. 1 Sleep onset latency assessed by parental estimation and actigraphy (Hvolby et al. 2008). Data are shown as means \pm standard deviations. Differences between the three groups were statistically significant for both the actigraphic measure $(p<0.01)$ and the parental measure $(p<0.001)$, as was the difference between the two measures $(p<0.001)$ across all groups (three-way analysis of variance, adjusted for sex and family type) (Hvolby et al. 2008). $A D H D$ attention-deficit/hyperactivity disorder

In subsequent actigraphic studies, differences between children with and without ADHD in sleep latency, sleep efficiency and total sleep time were statistically significant in one study (Moreau et al. 2013) but not in another (Wiebe et al. 2013). Waking after sleep onset was found to be increased in adolescents with ADHD (Mullin et al. 2011), and several actigraphic measures of sleep have also been reported to differ significantly in adults with ADHD, compared with controls (Boonstra et al. 2007; Gamble et al. 2013; Kooij et al. 2001; Van Veen et al. 2010). Actigraphic studies have also reported instability or increased night-to-night variability in sleep parameters in patients with ADHD compared with controls (Gruber and Sadeh 2004; Gruber et al. 2000; Hvolby et al. 2008; Moreau et al. 2013).

\section{Multiple sleep latency test}

The MSLT provides a measure of daytime sleepiness by timing the first signs of sleep during daytime nap periods (Spruyt and Gozal 2011). The technique is subject to substantial heterogeneity, possibly due to differences in methodology and patient populations among studies (Cortese et al. 2009; Golan et al. 2004; Lecendreux et al. 2000). In meta-analyses (Cortese et al. 2006a, 2009), the average time taken to fall asleep in MSLTs was statistically significantly shorter in patients with ADHD than in controls, based on two included studies (Golan et al. 2004; Lecendreux et al. 2000). Both studies also reported that greater proportions of children with ADHD fell asleep during testing than did controls (Golan et al. 2004; Lecendreux et al. 2000). More recent studies have found no significant differences between children with ADHD and controls in MSLT outcomes (Prihodova et al. 2010; Wiebe et al. 2013), although one of these reported statistically significant inter-test variability in the ADHD group (Prihodova et al. 2010). There is also little agreement among three studies that have investigated the question of whether MSLT results correlate with objective measures of nocturnal sleep in individuals with ADHD (Golan et al. 2004; Lecendreux et al. 2000; Wiebe et al. 2013).

\section{Subjective assessments}

Subjective measures of sleep in children are based on parent or child reports and include the BEARS sleep screening tool (Owens and Dalzell 2005), the Children's Sleep Habits Questionnaire (CSHQ) (Owens et al. 2000), the Children's Sleep Behavior Scale (CSBS) (Fisher et al. 1989) and sleep diaries (Hvolby et al. 2008, 2009). Adult instruments include the Pittsburgh Sleep Quality Index (Buysse et al. 1989). Instruments for subjective assessment of daytime sleepiness include the Epworth Sleepiness Scale.

The most recent meta-analysis of subjective studies found that ADHD was associated with statistically significant greater impairments in six parent-reported subjective measures of sleep in children than in controls (Cortese et al. 2009). The largest standardized mean difference was observed for bedtime resistance, followed by difficulty with morning awakenings, sleep onset difficulties, sleepdisordered breathing, night awakenings and daytime sleepiness. Other sleep problems reportedly associated with ADHD in children and/or adults include early and middle insomnia, nocturnal awakening, nocturnal activity, snoring, breathing difficulties, restless sleep, parasomnias, nightmares, daytime sleepiness, delayed sleep phase, short sleep time and anxiety around bedtime (Hansen et al. 2013; Hvolby et al. 2008, 2009; Spruyt and Gozal 2011; Yoon et al. 2012).

Association of particular sleep problems with ADHD subtypes

Different patterns of sleep impairment may be characteristic of ADHD subtypes (Gruber 2009). Some studies show that parent-reported sleep disturbances are more common in combined-type ADHD than in predominantly inattentive ADHD (Corkum et al. 1999; Mayes et al. 2009), while others describe greater daytime sleepiness in predominantly inattentive ADHD than in combined-type ADHD 
(Chiang et al. 2010; LeBourgeois et al. 2004; Lecendreux et al. 2000). However, differences in symptom severity between subtypes may confound the associations with sleep problems (Corkum et al. 2011). Hyperkinetic disorder (HKD) diagnosed according to the ICD-10 criteria is generally regarded as a more severe form of combined-type ADHD than that described by the DSM, and children with HKD exhibited profound sleep-related problems in a study using subjective parent ratings (Gomes et al. 2013). If different sleep problems are associated with different ADHD subtypes, then this represents another potentially uncontrolled variable in studies investigating the relationship between sleep and ADHD (Kirov et al. 2004).

Agreement and disagreement between subjective and objective measures of sleep

While laboratory studies are susceptible to artifacts (e.g., first-night effects), naturalistic studies are subject to uncontrolled variables such as parents' work schedules, parenting style, family structure, child habits and employment in teenagers (Beebe 2011). Several studies have revealed discrepancies between results obtained using objective and subjective measures of sleep in patients with ADHD (Choi et al. 2010; Corkum et al. 2001; Hvolby et al. 2008; Lim et al. 2008; Owens et al. 2009; Wiggs et al. 2005; Yoon et al. 2012). In one study in children, parental estimates of sleep onset latency exceeded actigraphic estimates in about $75 \%$ of cases, although mean sleep onset latency was longer in children with ADHD than in controls using both measures (Fig. 1) (Hvolby et al. 2008). Subjective reports may emphasize particularly problematic nights, which may not be captured in a single night's objective measurement, or by averaging objective measurements over several nights: indeed, intra-individual variability in sleep parameters is reportedly higher in patients with ADHD than in controls (Gruber and Sadeh 2004; Gruber et al. 2000; Lecendreux and Cortese 2007; Moreau et al. 2013; Tsai and Huang 2010). Parental sensitivity to behavioral problems at bedtime may also lead to differences compared with objective assessments (Hvolby et al. 2008; Owens et al. 2009; Yoon et al. 2012). In adults with ADHD, selfreported sleep time, quality and efficiency were lower than in controls, but this was found to correlate with polysomnographic measures of PLMS and not with polysomnographic measures of sleep efficiency, length or onset latency (Philipsen et al. 2005). In summary, the available methods for assessing sleep each present their own advantages and disadvantages, with no single technique providing a complete picture of the complex interactions between sleep and ADHD.

\section{Relationship of sleep disorders to ADHD}

Diagnosis of sleep disorders is based on formal subjective and/or objective criteria, such as the International Classification of Sleep Disorders (American Academy of Sleep Medicine 2005). Specific sleep disorders are associated with ADHD or ADHD-like symptoms, and systematic screening for sleep problems and disorders has been recommended during initial assessment and ongoing management of patients with ADHD (Cortese et al. 2013a). Inadequate sleep in children is known to have neurocognitive, neurobehavioral and functional manifestations that overlap with the core features of ADHD (O'Brien 2009; Owens et al. 2013). Experimental sleep restriction impacts on attention and higher-level cognitive function (Beebe 2011), and has been shown to affect neurobehavioral functioning in typically developing children (Gruber et al. 2011). No experimental study has yet shown that sleep restriction induces hyperactivity, impulsivity or externalizing behaviors in children (Beebe 2011), despite the perception that 'paradoxical' hyperactivity exists as a behavioral response to daytime sleepiness (Owens et al. 2013; Owens 2008). Recent observational studies in typically developing children have, however, shown that short sleep duration correlates with ADHD-like symptoms and behaviors scored by parents (Paavonen et al. 2009; Pesonen et al. 2010) and teachers (Gruber et al. 2012b).

Sleep-disordered breathing and obstructive sleep apnea

The term sleep-disordered breathing (SDB) describes a spectrum of conditions ranging from obstructive sleep apnea (OSA) to primary snoring (O'Brien 2009; Owens 2008). SDB has been consistently associated with neurobehavioral and neurocognitive deficits, including inattentive or ADHD-like symptoms (Beebe 2006; Beebe et al. 2004; Chervin et al. 2002, 2012; Gottlieb et al. 2003; Lal et al. 2012; O'Brien 2009; Owens 2008; Rosen et al. 2004; Soylu et al. 2013; Suratt et al. 2011). Furthermore, a recent systematic review indicated that the prevalence of OSA in patients with ADHD (25-30\%) is higher than in the general population (about $3 \%$ ) (Youssef et al. 2011). Indeed, US guidelines recommend that children undergoing evaluation for ADHD are assessed for sleep apnea (Wolraich et al. 2011).

Surgical treatment of children with OSA via adenotonsillectomy in prospective, interventional studies has been reported to be associated with improvements in neuropsychological behavior (Beebe 2006), academic performance (Gozal 1998) and ADHD-like symptoms (Soylu et al. 2013; Youssef et al. 2011). In children with diagnoses of ADHD and OSA, two prospective studies have 
demonstrated significant improvements in ADHD symptoms, including hyperactivity, following adenotonsillectomy (Chervin et al. 2006; Huang et al. 2007). There is also some evidence that positive airway pressure ventilation in patients with OSA may also be associated with improvements in ADHD-like symptoms (Youssef et al. 2011). Large-scale, randomized, controlled studies are warranted to investigate further the effect of OSA treatment in patients with ADHD (Youssef et al. 2011).

Restless legs syndrome and periodic limb movement disorder

Restless legs syndrome (RLS) is a neurological disorder characterized by an irresistible urge to move the legs to relieve uncomfortable sensations at rest (Picchietti and Picchietti 2010). Periodic limb movement disorder (PLMD) is a clinical syndrome characterized by PLMS of a specific nature and frequency determined by polysomnography (Picchietti and Picchietti 2010). While $2 \%$ of typically developing children and adolescents (aged 8-17 years) are reported to meet the diagnostic criteria for RLS (Picchietti et al. 2007), up to $44 \%$ of children with ADHD have symptoms of RLS, and $26 \%$ of children with RLS have symptoms of ADHD (Cortese et al. 2005; Owens 2008). Accordingly, Cortese et al. have emphasized the importance of identifying RLS during clinical evaluation of children with ADHD symptoms (Cortese et al. 2006b). The recently revised diagnostic criteria for RLS in children introduced pediatric terms and prompts to allow the clinician to recognize typical descriptions of RLS symptoms, which must be in the child's own words (Picchietti et al. 2013). As described previously, increased PLMS in patients with ADHD compared with controls is a common finding in polysomnographic studies. The impact of RLS or PLMD on sleep could lead not only to the diurnal manifestation of ADHD-like symptoms but also to bedtime resistance, which may be mistaken for opposition or defiance, due to the unpleasant symptoms (Cortese et al. 2006b).

\section{Circadian-rhythm sleep disorders}

The major feature of circadian-rhythm sleep disorders is the misalignment of sleep pattern timing with the terrestrial cycle, leading to disrupted sleep and impaired functioning. In delayed sleep-phase disorder, sleeping and waking occur later than normal, and this may manifest as sleep onset insomnia, evening diurnal preference and difficulty waking. Such sleep problems are common, especially during adolescence: a meta-analysis of adolescent sleep studies revealed a worldwide delayed sleep-wake behavior pattern that was consistent with delayed sleep-phase disorder and resulted in decreased total sleep time and daytime sleepiness (Gradisar et al. 2011). There is evidence to suggest that ADHD may be associated with disturbances of the circadian rhythm. A delayed pattern of melatonin secretion in children with ADHD compared with controls has been described (Van der Heijden et al. 2005, 2007). Children with ADHD have also been reported to exhibit stronger circadian evening tendencies than controls, as assessed using the child morning-evening preference scale. Scores on this parent-rated instrument were correlated with both parental and polysomnographic measures of sleep onset latency (Gruber et al. 2012a). In adults with ADHD, disturbances in diurnal rhythms of endocrine secretion, CLOCK gene expression and physical activity have been reported (Baird et al. 2012; Bijlenga et al. 2013). Furthermore, delayed sleep timing in adults with ADHD and comorbid insomnia compared with controls has been documented (Van Veen et al. 2010) and shown to correlate with the severity of ADHD symptoms (Gamble et al. 2013).

Interaction of obesity with sleep disorders and ADHD

There is good evidence from cross-sectional studies for an association of ADHD with obesity: The prevalence of ADHD is higher than expected in people with obesity sampled at obesity clinics, and the body mass index of patients with ADHD is higher than average (Cortese et al. 2008a). Furthermore, in a 33-year longitudinal study, $41.4 \%$ of adults who had combined-type ADHD as children were obese, compared with $21.6 \%$ of those without a childhood diagnosis of ADHD (Cortese et al. 2013c). Obesity is, in turn, correlated with sleep-disordered breathing and other sleep disorders (Cortese et al. 2008b), short sleep duration (Taheri et al. 2004) and short time in bed (Hart et al. 2013). Abnormal eating behaviors associated with ADHD (e.g., impulsive eating) might contribute to obesity (Cortese and Vincenzi 2012), and in adolescents with obesity but without diagnosed ADHD, daytime sleepiness has been reported to correlate with ADHD symptom ratings (Cortese et al. 2007). Together, these data suggest a complex interplay between ADHD, obesity and sleep problems.

\section{Effects of ADHD medications on sleep}

ADHD medications are known to affect sleep in many individuals, and guidelines recommend that sleep is carefully assessed before starting ADHD pharmacotherapy (Graham et al. 2011; Wolraich et al. 2011). Sleep disturbances in patients with ADHD, including those associated with ADHD medications, may be addressed via 
pharmacological and behavioral interventions, with the latter forming part of the recommended multimodal strategy (Cortese et al. 2013a).

\section{Pharmacotherapy with stimulants}

The effects of stimulants on sleep in patients with ADHD differ from patient to patient and reflect the underlying complexity of the links between ADHD and sleep disturbance (Graham et al. 2011). The sympathomimetic action of stimulants promotes wakefulness in most people, underlying their use in the treatment of narcolepsy (Morgenthaler et al. 2007). While there is evidence that stimulants are associated with disrupted or disturbed sleep in patients with ADHD (Ironside et al. 2010; Nutt et al. 2007; Spruyt and Gozal 2011; Stein 1999), clinical experience also indicates that stimulants produce paradoxical effects (Bradley 1937), whereby alleviation of symptoms can calm patients and promote sleep (Jerome 2001; Kinsbourne 1973; Kooij et al. 2001; Kratochvil et al. 2005). Furthermore, because of the potential for symptom rebound as blood drug concentrations wane (Carlson and Kelly 2003), an additional dose of a short-acting stimulant, or the use of a formulation with an increased duration of action, may prevent sleep disturbances resulting from worsening of hyperactivity or behavioral difficulties at bedtime (Cortese et al. 2013a, b; Lecendreux et al. 2000).

In clinical trials using objective sleep measures, immediate-release methylphenidate has been reported to increase sleep onset latency and/or to decrease total sleep time in patients with ADHD (Boonstra et al. 2007; Galland et al. 2010; Greenhill et al. 1983; Sangal et al. 2006), with sleep quality either unaffected (Galland et al. 2010) or improved (Boonstra et al. 2007; Sobanski et al. 2008). A recent metaanalysis of six actigraphic studies in children with ADHD reported statistically significant lower daytime activity, longer sleep onset latency, lower total sleep time and lower sleep efficiency with immediate-release methylphenidate treatment than with placebo (De Crescenzo et al. 2014). Both amfetamine and methylphenidate are associated with treatment-emergent adverse events (TEAEs) of insomnia in clinical studies (Efron et al. 1997; Stein et al. 2011).

Long-acting stimulants are available in many different formulations (Hodgkins et al. 2012). This section focuses on osmotic-release oral system methylphenidate (OROSMPH) and lisdexamfetamine dimesylate (LDX), both of which are recently developed and widely used ADHD medications with daily durations of efficacy of at least $12 \mathrm{~h}$ post-dose (Coghill and Seth 2006; Lakhan and Kirchgessner 2012; Setyawan et al. 2013a, b; Steer et al. 2012).

OROS-MPH combines an immediate-release bolus with a two-stage extended-release technology to provide an ascending profile of drug delivery similar to three daily doses of immediate-release methylphenidate (Swanson et al. 2003). In an open-label polysomnographic study in children with ADHD, the only statistically significant effects of OROS-MPH treatment were a decrease in the number of night-time awakenings and an increase in the percentage of stage 2 sleep, compared with pre-treatment baseline (Kim et al. 2010). Based on parental sleep diaries, both OROS-MPH and another extended-release methylphenidate formulation led to statistically significant reductions in total sleep time 1-4 weeks after initiation of treatment in a randomized study in children with ADHD (Lee et al. 2012). In a randomized, double-blind, placebocontrolled study, the majority of children in all three treatment groups (OROS-MPH, placebo or immediaterelease methylphenidate three times daily) continued to have good or excellent sleep quality based on parent ratings at 2 and 4 weeks after initiation of treatment (Wolraich et al. 2001). Sleep quality was also rated as good or excellent by parents after 1 and 12 months of open-label OROS-MPH treatment in children with ADHD (Wilens et al. 2003). Table 1 shows a summary of the proportions of patients experiencing TEAEs of insomnia in randomized, double-blind, placebo-controlled, parallel-group clinical studies of OROS-MPH.

LDX is the only stimulant prodrug. After oral administration, rate-limiting enzymatic hydrolysis of LDX in the bloodstream releases the pharmacologically active $d$-amfetamine moiety from the lysine conjugate (Steer et al. 2012). LDX treatment was not associated with impairments in sleep quality or quantity in clinical trials using objective sleep measures in adults with ADHD (Adler et al. 2009a; Surman and Roth 2011) and children with ADHD (Giblin and Strobel 2011) (Fig. 2). Table 2 shows a summary of the proportions of patients experiencing TEAEs of insomnia in randomized, double-blind, placebo-controlled, parallel-group clinical studies of LDX.

\section{Pharmacotherapy with non-stimulants}

In contrast to stimulants, somnolence is the most common sleep-related adverse event associated with atomoxetine (a noradrenaline reuptake inhibitor approved for treatment of ADHD). In a 2009 systematic review, the frequency of somnolence reported as a TEAE in placebo-controlled clinical trials of atomoxetine was reported to range from 15 to $17 \%$ (Garnock-Jones and Keating 2009). In a randomized, double-blind trial, atomoxetine was associated with a smaller increase in sleep onset latency, a lower frequency of insomnia, a higher frequency of somnolence and smaller effects on subjective measures of sleep than methylphenidate taken three times daily (Sangal et al. 2006). Lower frequencies of insomnia and higher frequencies of somnolence with atomoxetine than with long-acting stimulants 
Table 1 Frequency of TEAEs of insomnia (or similar) in randomized, double-blind, placebo-controlled, parallel-group clinical studies of OROS-MPH in patients with ADHD

\begin{tabular}{|c|c|c|c|c|}
\hline Study & Age of population, years & Duration, weeks & Treatment $(n)$ & $\begin{array}{l}\text { Proportion of patients } \\
\text { reporting a TEAE, } \%\end{array}$ \\
\hline \multirow[t]{2}{*}{ Medori et al. (2008) } & \multirow[t]{2}{*}{$18-65$} & \multirow[t]{2}{*}{5} & Placebo (96) & 7.3 \\
\hline & & & OROS-MPH (305) & 13.4 \\
\hline \multirow[t]{2}{*}{ Biederman et al. (2006) } & \multirow[t]{2}{*}{$19-60$} & \multirow[t]{2}{*}{6} & Placebo (74) & $5^{\mathrm{a}}$ \\
\hline & & & OROS-MPH (67) & $18^{\mathrm{a}}$ \\
\hline \multirow[t]{2}{*}{ Biederman et al. (2010) } & \multirow[t]{2}{*}{$19-60$} & \multirow[t]{2}{*}{$6^{\mathrm{b}}$} & Placebo (109) & $4^{\mathrm{c}}$ \\
\hline & & & OROS-MPH (114) & $11^{\mathrm{c}}$ \\
\hline \multirow[t]{2}{*}{ Adler et al. (2009b) } & \multirow[t]{2}{*}{$18-65$} & \multirow[t]{2}{*}{7} & Placebo (116) & $5.2(3.4)^{\mathrm{d}}$ \\
\hline & & & OROS-MPH (110) & $9.1(7.3)^{\mathrm{d}}$ \\
\hline \multirow[t]{3}{*}{ Newcorn et al. (2008) } & \multirow[t]{3}{*}{$6-16$} & \multirow[t]{3}{*}{6} & Placebo (74) & $1^{\mathrm{e}}$ \\
\hline & & & OROS-MPH (219) & $13^{\mathrm{e}}$ \\
\hline & & & Atomoxetine (221) & $7^{\mathrm{e}}$ \\
\hline \multirow[t]{3}{*}{ Findling et al. (2008) } & \multirow[t]{3}{*}{$6-12$} & \multirow[t]{3}{*}{7} & Placebo (85) & 4.7 \\
\hline & & & OROS-MPH (91) & 7.7 \\
\hline & & & Transdermal methylphenidate (98) & 13.3 \\
\hline \multirow[t]{3}{*}{ Casas et al. (2013) } & \multirow[t]{3}{*}{$18-65$} & \multirow[t]{3}{*}{13} & Placebo (97) & $11.3(2.1)^{\mathrm{d}}$ \\
\hline & & & OROS-MPH 54 mg (89) & $14.6(7.9)^{\mathrm{d}}$ \\
\hline & & & OROS-MPH 72 mg (92) & $16.3(9.8)^{\mathrm{d}}$ \\
\hline
\end{tabular}

Randomized-withdrawal studies are excluded

$A D H D$ attention-deficit/hyperactivity disorder, $O R O S-M P H$ osmotic-release oral system methylphenidate, TEAE treatment-emergent adverse event

a Frequency of 'sleep problems'

b Acute efficacy phase

c TEAEs reported on two or more visits

${ }^{d}$ Frequency of initial insomnia

e Includes insomnia, initial insomnia, middle insomnia and late insomnia

have been reported as TEAEs in randomized, double-blind, parallel-group efficacy studies (Dittmann et al. 2013; Newcorn et al. 2008). Dosing in the evening rather than in the morning has been found to reduce daytime somnolence with atomoxetine (Block et al. 2009).

An extended-release formulation of guanfacine, a selective $\alpha_{2}$-adrenoceptor agonist, is approved in North America for the treatment of children and adolescents with ADHD, both as a monotherapy and as an adjunct to stimulant treatment. Somnolence is one of the most commonly reported TEAEs in clinical trials of extended-release guanfacine (either alone or when coadministered with a stimulant) (Faraone et al. 2013). The effects of guanfacine on ADHD symptoms have been suggested to be independent of its sedative properties (Kollins et al. 2011). Extended-release clonidine (another selective $\alpha_{2}$-adrenoceptor agonist) is also approved in North America with a similar indication (Childress and Sallee 2012) and is associated with somnolence (Cortese et al. 2013b).
Management of sleep problems in patients with ADHD

Both European and US guidelines recommend assessment of sleep disturbance during evaluation of an individual for suspected ADHD, and before initiation of pharmacotherapy (Graham et al. 2011; Wolraich et al. 2011). This approach enables any effects of the disorder on sleep to be distinguished from those of medication (Cortese et al. 2013b). Clinicians have been advised to use sleep diaries and questionnaires for routine screening and follow-up, together with specific screening for RLS and polysomnography when a physical sleep disorder is suspected (Cortese et al. 2013b). In developing a multimodal treatment plan for patients with ADHD, consideration should be given to interventions focused on improving sleep and bedtime behavior (Lecendreux and Cortese 2007). Both non-pharmacological and pharmacological interventions are available for improving sleep in patients with ADHD, and are applicable to sleep disturbance associated with ADHD medication and with the disorder itself. Potential 
Fig. 2 a, b Polysomnographic, c parent-rated subjective and d actigraphic outcomes from a double-blind, randomized, parallel-group study of the effects of LDX treatment on sleep in 24 children with ADHD (Giblin and Strobel 2011). ${ }^{*} p<0.0001$ versus baseline. $A D H D$ attention-deficit/ hyperactivity disorder, $\mathrm{CSHQ}$ Children's Sleep Habits Questionnaire, $L D X$ lisdexamfetamine
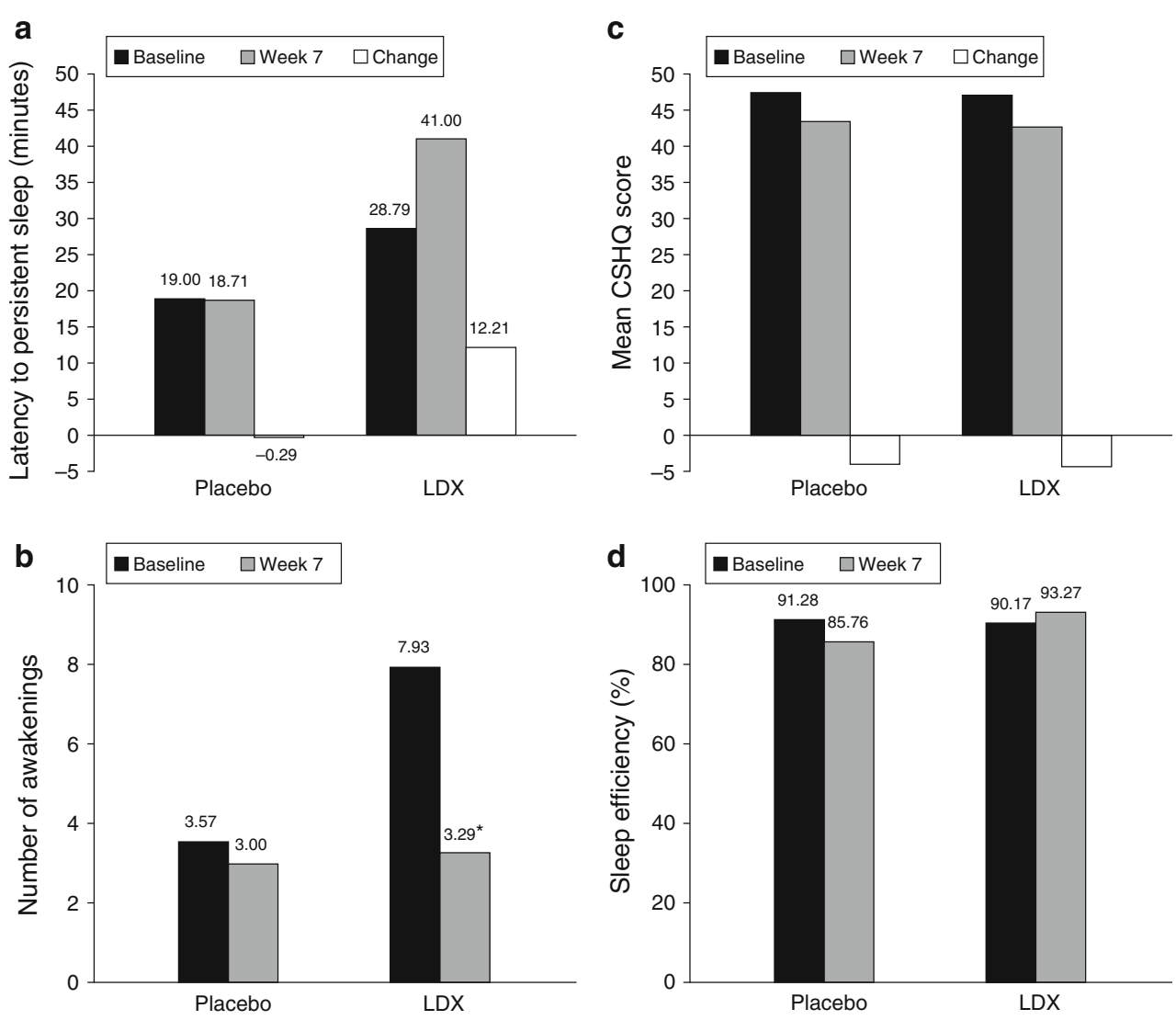

strategies for managing sleep disturbances during treatment with ADHD medications are summarized in Table 3.

\section{Sleep hygiene}

Healthy sleep practices include the following: a regular sleep/wake schedule; adequate opportunity for sleep; calming and structured bedtime routines; avoidance of caffeine, large amounts of liquids, naps, exercise and alerting activities (e.g., use of electronic devices) soon before bedtime; sleeping only in bed and using the bed only for sleeping; and attention to environmental factors such as bedroom furniture, lighting and temperature (Cortese et al. 2013a; Owens 2008; Yoon et al. 2012). In a study of children with ADHD and initial insomnia receiving stimulants, implementing sleep hygiene reduced sleep onset delay to below $60 \mathrm{~min}$ in about $20 \%$ of patients, with an overall effect size of 0.67 (Weiss et al. 2006). Implementing healthy sleep practices is the recommended first-line option for addressing problems with sleep in both medicated and un-medicated patients with ADHD (Cortese et al. 2013b; Lecendreux and Cortese 2007).
Behavioral interventions

Established behavioral interventions for insomnia in typically developing children include parent education, graduated extinction (ignoring disruptive behaviors for a predetermined period) and bedtime fading, which involves identifying a bedtime at which the child falls asleep within about $15 \mathrm{~min}$, and gradually setting bedtime earlier until the desired bedtime is achieved, while keeping wake time fixed and disallowing sleep at other times (Mindell et al. 2006; Vriend and Corkum 2011). Clinical studies of behavioral interventions to improve sleep in children with ADHD are limited and have not demonstrated any effect on ADHD symptoms (Cortese et al. 2013a). A pilot study indicated that a sleep program involving face-to-face and telephone contact with a specialist pediatrician or child psychiatrist improved children's sleep, quality of life and psychosocial functioning, based on parent reports after 5 months (Sciberras et al. 2011). This approach is under evaluation in a larger randomized, controlled study (Sciberras et al. 2010). Case reports also indicate efficacy of behavioral programs in reducing the severity of dyssomnia in children with ADHD (Mindell et al. 2006). 
Table 2 Frequency of TEAEs of insomnia (or similar) in randomized, double-blind, placebo-controlled, parallel-group clinical studies of LDX in patients with ADHD

\begin{tabular}{|c|c|c|c|c|}
\hline Study & $\begin{array}{l}\text { Age of population, } \\
\text { years }\end{array}$ & $\begin{array}{l}\text { Duration, } \\
\text { weeks }\end{array}$ & $\begin{array}{l}\text { Treatment } \\
(n)\end{array}$ & $\begin{array}{l}\text { Proportion of patients } \\
\text { reporting a TEAE, } \%\end{array}$ \\
\hline \multirow{2}{*}{ Biederman et al. (2007) } & \multirow{2}{*}{$6-12$} & \multirow[t]{2}{*}{4} & Placebo (72) & 2.8 \\
\hline & & & LDX (218) & 18.8 \\
\hline \multirow[t]{2}{*}{ Adler et al. (2008) } & \multirow[t]{2}{*}{$18-55$} & \multirow[t]{2}{*}{4} & Placebo (62) & 5 \\
\hline & & & LDX (358) & $17-21^{\mathrm{a}}$ \\
\hline \multirow[t]{2}{*}{ Findling et al. (2011) } & \multirow[t]{2}{*}{$13-17$} & \multirow[t]{2}{*}{4} & Placebo (77) & 3.9 \\
\hline & & & LDX (223) & 11.2 \\
\hline \multirow[t]{3}{*}{ Coghill et al. (2013) } & \multirow[t]{3}{*}{$6-17$} & \multirow[t]{3}{*}{7} & Placebo (110) & $0.0(0.9)^{\mathrm{c}}$ \\
\hline & & & LDX (111) & $14.4(2.7)^{\mathrm{c}}$ \\
\hline & & & OROS-MPH $(111)^{\mathrm{b}}$ & $8.1(6.3)^{\mathrm{c}}$ \\
\hline \multirow[t]{2}{*}{ Adler et al. (2013) } & \multirow[t]{2}{*}{$18-55^{\mathrm{d}}$} & \multirow[t]{2}{*}{10} & Placebo (80) & 3.8 \\
\hline & & & LDX (79) & 12.7 \\
\hline
\end{tabular}

Randomized-withdrawal studies are excluded

$A D H D$ attention-deficit/hyperactivity disorder, $L D X$ lisdexamfetamine dimesylate, TEAE treatment-emergent adverse event

${ }^{a}$ Range across forced-dose groups (30,50 or $70 \mathrm{mg} /$ day)

${ }^{b}$ Reference arm (active control)

${ }^{c}$ Frequency of initial insomnia

d Patients with ADHD and executive function deficits

Table 3 Recommended strategies for managing sleep disturbances during treatment with ADHD medications (Cortese et al. 2013b)

Monitoring: insomnia associated with stimulants may attenuate after 1-2 months (Lecendreux and Cortese 2007)

Considering if it is possible to stop the medication

Implementing sleep hygiene/behavioral measures

Reviewing the possible causes of sleep problems

Treating RLS

Adding small, short-acting stimulant doses in the early evening (if rebound effect occurs)

Reducing stimulant dose

Switching to an alternative class of stimulant

Switching to an alternative stimulant formulation

Considering use of a non-stimulant (e.g., atomoxetine)

Considering melatonin treatment

$A D H D$ attention-deficit/hyperactivity disorder, $R L S$ restless legs syndrome

The ball blanket

Ball blankets (Fig. 3) are filled with loose balls to stimulate sensory receptors in the skin, muscles and joints, which transmit inhibitory signals to the central nervous system (Hvolby and Bilenberg 2011). In a study in children with ADHD, the use of ball blankets was found to reduce sleep onset latency, the number of awakenings and intra-individual variability in sleep parameters (Hvolby and Bilenberg 2011).
Pharmacological strategies

In addition to adjusting dose, class, formulation or regimen of ADHD medications, sleep problems in patients with ADHD may be addressed via additional medications (Table 3). In patients with psychiatric comorbidities, it should be borne in mind that other medications (e.g., antidepressants) may also affect sleep. Implementation of healthy sleep practices should precede pharmacological interventions targeted at specific sleep disorders in patients with ADHD (Cortese et al. 2013a).

Iron deficiency has been implicated in the etiology of both RLS and ADHD, with potential links to alteration of dopamine transporter expression and the synthesis and catabolism of monoaminergic neurotransmitters (Allen and Earley 2007; Cortese et al. 2005, 2012). A small, randomized study of iron supplementation in children with ADHD detected a statistically significant reduction of ADHD symptoms (Konofal et al. 2008). Monitoring serum ferritin levels has been proposed for children with suspected RLS (Picchietti and Picchietti 2010), and there is some evidence that iron supplementation may be effective in relieving the symptoms of RLS in children (Cortese et al. 2013a). The role of monoamine neurotransmission in ADHD and RLS was investigated more directly in a double-blind, placebo-controlled trial in 29 children with ADHD or ADHD and RLS/PLMS. In this study, levodopa treatment slightly improved PLMS and/or RLS symptoms, but did not affect other sleep parameters, ADHD symptoms 

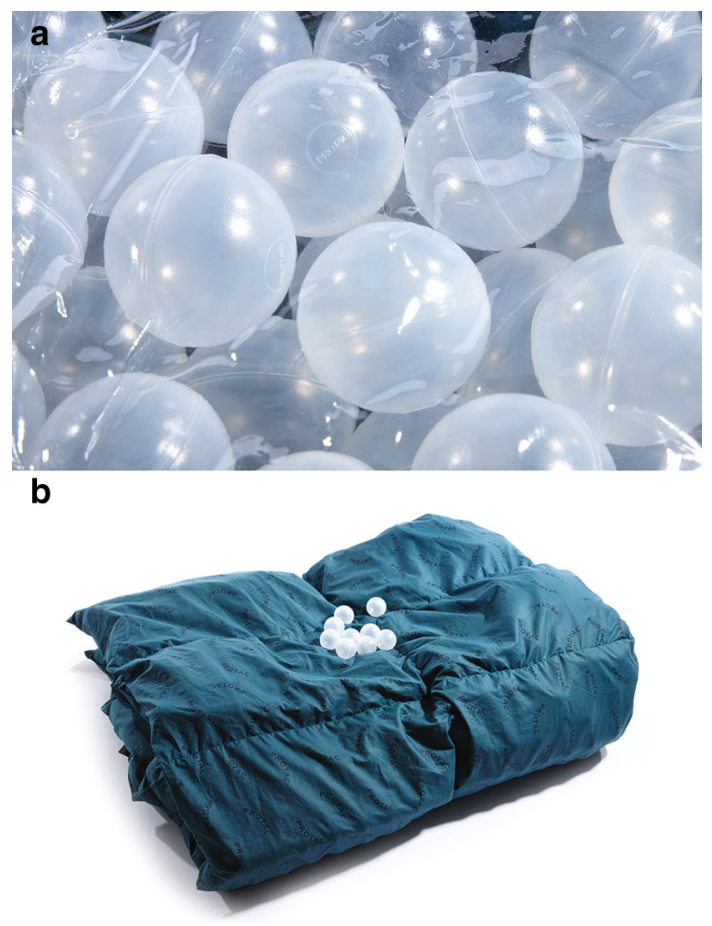

Fig. 3 Ball blanket. a Plastic balls, diameter $49 \mathrm{~mm}$ and b cotton blanket containing $7 \mathrm{~kg}$ of balls and measuring $140 \times 200 \mathrm{~cm}$

or performance in neuropsychometric tests (England et al. 2011). However, a subsequent subgroup analysis of this study failed to confirm the effect of levodopa on PLMS (Ferri et al. 2013). These results suggest that further work is needed to unravel the relationship, if any, between dopamine, ADHD and RLS/PLMS. No therapies have yet received regulatory approval for treating RLS in children (Cortese et al. 2013a).

Patients with ADHD and circadian-rhythm disorder are reported to exhibit a delayed pattern of melatonin secretion. Melatonin is classified as a dietary supplement in the USA but is subject to drug regulation in Europe (Bendz and Scates 2010). Two randomized, double-blind, placebocontrolled trials (Van der Heijden et al. 2007; Weiss et al. 2006) and a preliminary open-label study (Tjon Pian Gi et al. 2003) have indicated that melatonin treatment is effective in reducing sleep onset delay in children with ADHD (Cortese et al. 2013a).

Hypnotic agents, including zolpidem, mirtazapine, trazodone and antihistamines, have been used off-label in clinical practice to treat insomnia in children with ADHD (Kratochvil et al. 2005) and some have been evaluated in clinical trials (Cortese et al. 2013b), but their use does not form part of current clinical guidelines. Clonidine has also been suggested as a treatment option for stimulant-associated sleep onset delay in patients with ADHD (in an immediate-release formulation rather than the extended- release formulation used as an ADHD therapy) (Prince et al. 1996; Wilens et al. 1994).

Real-world data on sleep medication use in patients with ADHD is scarce. In observational study in a population of children with ADHD, $63 \%$ of whom had moderate or severe sleep problems, $19 \%$ took clonidine and $9 \%$ took melatonin during the 1 -week reporting period (none took antihistamines, benzodiazapenes or dopamine agonists) (Efron et al. 2014).

\section{A conceptual model of the interactions of ADHD with sleep}

Associations between ADHD and sleep disorders and subjective or objective measures of sleep or sleep disturbance do not provide information on causation. As an interpretative aid, this section presents a conceptual model of the potential relationships between sleep problems and ADHD or ADHD-like symptoms (Fig. 4). This theoretical framework is made up of four hypothetical scenarios.

In one scenario, ADHD leads directly to problems with sleep (Fig. 4, left-hand panel). This may be due to hyperactivity, nocturnal motricity or behavior (e.g., bedtime resistance). This scenario may be more pertinent to patients with hyperactive symptoms than to those with predominantly inattentive ADHD. If sleep problems are a consequence of ADHD symptoms, treatment with stimulants may help a patient to sleep by reducing these symptoms. Insufficient duration of efficacy may, however, lead to symptom rebound at bedtime.

In a contrasting scenario, disturbed sleep is responsible for daytime symptoms, behaviors and functional impairments that are characteristic of ADHD (Fig. 4, right-hand panel). The strongest evidence for a sleep disorder giving rise to ADHD or ADHD-like symptoms is the amelioration of such symptoms after surgical intervention to improve nocturnal breathing. It has been recommended that primary sleep disorders are excluded before diagnosing ADHD (Cortese et al. 2006b, 2013a; Lecendreux and Cortese 2007). In this situation, psychostimulant medications might be ineffective or could even exacerbate sleep problems. In contrast, treating an underlying sleep disorder could result in daytime improvements (O'Brien 2009). That successful treatment of OSA, RLS and delayed sleep-phase disorder can lead to improvements in ADHD symptoms is borne out by case studies (Miano et al. 2013).

In another scenario, sleep disturbances and ADHD are coincident, but may exacerbate each other in a feed-forward loop (Fig. 4, upper-middle panel). Individuals with ADHD could be both more vulnerable to the effects of sleep disturbance and more prone to disturbed sleep than typically developing children (Owens et al. 2013). The 
Fig. 4 Conceptual model of the modes of interaction between ADHD and sleep. $A D H D$ attention-deficit/hyperactivity disorder

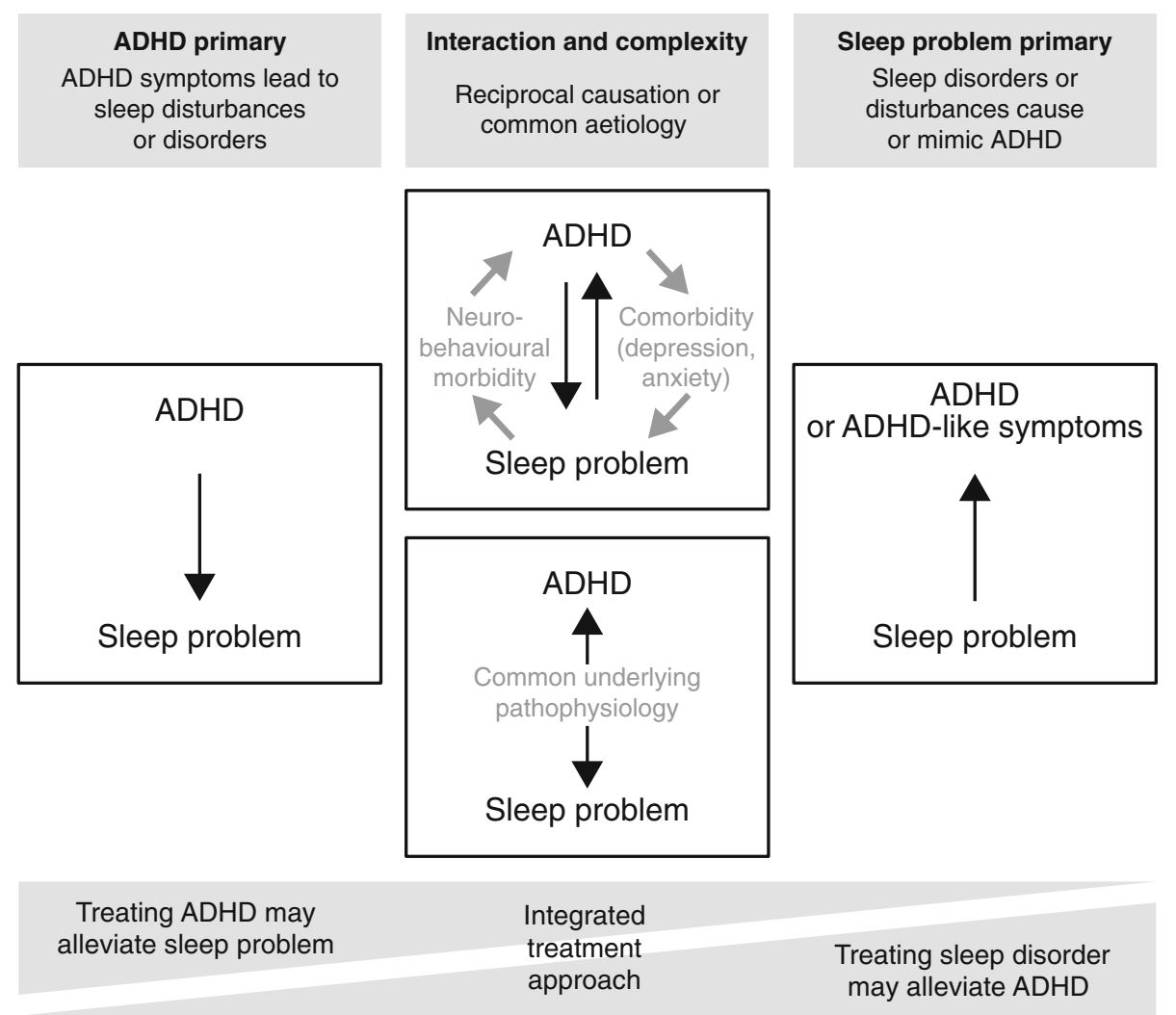

choice of treatment in this situation is complex because medications could have opposing or mixed effects on sleep. Psychiatric comorbidities are common in children with ADHD, and these may be associated with sleep problems. Furthermore, daytime sleepiness has been reported to be associated with worsened internalizing symptoms in children with anxiety disorder, suggesting that poor sleep may negatively affect emotional regulation as well as attentional functioning (Hansen et al. 2013). The possible interplay between sleep, ADHD and anxiety in children may be related to the alterations observed in sleep-deprived individuals in overlapping brain mechanisms involved in alertness and reward pathways (Gruber 2014). Sleep disturbances in ADHD can, however, occur independently of psychiatric comorbidities, as demonstrated in studies employing psychiatric control groups (Hvolby et al. 2008). Nevertheless, comorbid psychiatric disorders (both internalizing and externalizing) may further exacerbate both sleep problems and ADHD symptoms in patients with ADHD.

In a final scenario, common or overlapping neurobiological disease mechanisms are hypothesized to give rise to both ADHD and sleep disturbance (Fig. 4, lower-middle panel). Circadian-rhythm disorders, sleep/wake disorders and delayed sleep-phase disorder could share pathophysiological mechanisms with ADHD. There may be a genetically determined predisposition to sleep dysregulation in at least a subset of individuals with ADHD (Owens et al. 2013). Intra-individual variability in neuropsychological tasks, rather than a constant level of impairment, is characteristic of ADHD (Spencer et al. 2009; Tamm et al. 2012), and a similar picture of volatility and unpredictability is observed in sleep patterns in children with ADHD (Gruber and Sadeh 2004; Gruber et al. 2000; Lecendreux and Cortese 2007; Tsai and Huang 2010). Furthermore, sleep duration decreases during development, and a more rapid decrease compared with normative centiles at 3-5 years of age has been reported to be a significant predictor of subsequent ADHD (Scott et al. 2013).

\section{Conclusions}

ADHD is commonly associated with specific sleep disorders and objectively or subjectively assessed sleep disturbances. The relationship between ADHD and sleep problems is complex and bidirectional, and is modulated by interactions with ADHD medications and by psychiatric comorbidities and associated medications. Understanding these associations and relationships is important when assessing and managing patients with ADHD. As recommended in current guidelines, primary sleep disorders (specifically SDB/OSA and PLMD/RLS) should be ruled out before diagnosing or treating ADHD. Obesity and 
psychiatric comorbidities (e.g., anxiety and depression) can also lead to sleep problems, and need to be identified and treated appropriately. The multifaceted effects of stimulant pharmacotherapy on sleep in patients with ADHD are particularly important for clinicians to understand when evaluating treatment options for patients. Stimulant medications may disrupt or improve sleep in different patients, depending not only on the nature of the patient's illness, but also on the drug dose, class, formulation and duration of efficacy. Effective management of sleep problems associated with ADHD and its treatment may not only alleviate sleep-related symptoms, but also improve quality of life in parents or carers of children with disruptive bedtime behavior or insomnia.

In the near term, new understanding of how sleep interacts with ADHD and how this affects treatment choices is likely to come from clinical studies. Polysomnographic studies need to be larger and better controlled than previous studies, and should not overlook subtle polysomnographic signals such as microarousals and the time structure of PLMS. There is also a need to follow up the recent data indicating a link between ADHD, obesity, daytime sleepiness and circadian-rhythm alterations. Conspicuously absent from the current literature is any convincing demonstration that pharmacological or nonpharmacological intervention to improve sleep actually leads to improved ADHD symptoms or reduced functional impairment associated with the disorder. Similarly, as children become adolescents, they may experience sleep loss, but do any adolescents benefit from more or better sleep in terms of preventing worsening of ADHD? Crucial to both these questions is the possibility that specific ADHD phenotypes are associated with, or characterized by, particular types of sleep-related problems. In addition to helping clinicians make treatment decisions, the ability to subcategorize patients with ADHD based on their sleep phenotype may help shed light on areas where current data are conflicting. Furthermore, such phenotypic classification is probably essential for increased sensitivity in genomic screens for ADHD-associated polymorphisms. The overlapping neurochemical and neuroanatomical systems involved in regulating sleep, attention, arousal and circadian rhythms are the subjects of current basic research (Owens et al. 2013). Whether enhanced understanding of these mechanisms in health and disease or the use of stateof-the-art genetic and neuroimaging tools will lead to the development of new therapies or preventative strategies for ADHD are questions for the future.

Acknowledgments Shire provided funding to Oxford PharmaGenesis $^{\mathrm{TM}}$ Ltd for writing and editorial support for this publication. Dr. M. Cottingham and Dr. E. Southam of Oxford PharmaGenesis ${ }^{\text {TM }}$ Ltd provided writing assistance under the direction of the author. Editorial assistance in editing, fact checking, formatting, proofreading and submission was also provided by Oxford PharmaGenesis ${ }^{\text {TM }}$ Ltd. Shire develops and markets drugs to treat psychiatric disorders, including ADHD.

Conflict of interest The author declares he has no conflict of interest.

Open Access This article is distributed under the terms of the Creative Commons Attribution License which permits any use, distribution, and reproduction in any medium, provided the original author(s) and the source are credited.

\section{References}

Adler LA, Goodman DW, Kollins SH, Weisler RH, Krishnan S, Zhang Y, Biederman J (2008) Double-blind, placebo-controlled study of the efficacy and safety of lisdexamfetamine dimesylate in adults with attention-deficit/hyperactivity disorder. J Clin Psychiatry 69:1364-1373

Adler LA, Goodman D, Weisler R, Hamdani M, Roth T (2009a) Effect of lisdexamfetamine dimesylate on sleep in adults with attention-deficit/hyperactivity disorder. Behav Brain Funct 5:34. doi:10.1186/1744-9081-5-34

Adler LA, Zimmerman B, Starr HL, Silber S, Palumbo J, Orman C, Spencer T (2009b) Efficacy and safety of OROS methylphenidate in adults with attention-deficit/hyperactivity disorder: a randomized, placebo-controlled, double-blind, parallel group, dose-escalation study. J Clin Psychopharmacol 29:239-247. doi:10.1097/JCP.0b013e3181a390ce

Adler LA, Dirks B, Deas PF, Raychaudhuri A, Dauphin MR, Lasser RA, Weisler RH (2013) Lisdexamfetamine dimesylate in adults with attention-deficit/hyperactivity disorder who report clinically significant impairment in executive function: results from a randomized, double-blind, placebo-controlled study. J Clin Psychiatry 74:694-702. doi:10.4088/JCP.12m08144

Allen RP, Earley CJ (2007) The role of iron in restless legs syndrome. Mov Disord 22(Suppl 18):S440-S448. doi:10.1002/mds.21607

American Academy of Sleep Medicine (2005) The international classification of sleep disorders, 2nd edn. American Academy of Sleep Medicine, Westchester

American Psychiatric Association (1980) Diagnostic and statistical manual of mental disorders, 3rd edn. American Psychiatric Association, Washington

American Psychiatric Association (2013) Diagnostic and statistical manual of mental disorders, 5th edn (DSM-5). American Psychiatric Publishing, Arlington

Baird AL, Coogan AN, Siddiqui A, Donev RM, Thome J (2012) Adult attention-deficit hyperactivity disorder is associated with alterations in circadian rhythms at the behavioural, endocrine and molecular levels. Mol Psychiatry 17:988-995. doi:10.1038/ mp.2011.149

Barkley RA (1990) Attention-deficit-hyperactivity disorder: a handbook for diagnosis and treatment. Guildford Press, New York

Beebe DW (2006) Neurobehavioral morbidity associated with disordered breathing during sleep in children: a comprehensive review. Sleep 29:1115-1134

Beebe DW (2011) Cognitive, behavioral, and functional consequences of inadequate sleep in children and adolescents. Pediatr Clin North Am 58:649-665. doi:10.1016/j.pcl.2011.03.002

Beebe DW, Wells CT, Jeffries J, Chini B, Kalra M, Amin R (2004) Neuropsychological effects of pediatric obstructive sleep apnea. J Int Neuropsychol Soc 10:962-975 
Bendz LM, Scates AC (2010) Melatonin treatment for insomnia in pediatric patients with attention-deficit/hyperactivity disorder. Ann Pharmacother 44:185-191. doi:10.1345/aph.1M365

Bessey M, Richards J, Corkum P (2013) Sleep lab adaptation in children with attention-deficit/hyperactivity disorder and typically developing children. Sleep Disord 2013:698957. doi:10. $1155 / 2013 / 698957$

Biederman $\mathrm{J}$ et al (2006) A randomized, placebo-controlled trial of OROS methylphenidate in adults with attention-deficit/hyperactivity disorder. Biol Psychiatry 59:829-835. doi:10.1016/j. biopsych.2005.09.011

Biederman J, Krishnan S, Zhang Y, McGough JJ, Findling RL (2007) Efficacy and tolerability of lisdexamfetamine dimesylate (NRP104) in children with attention-deficit/hyperactivity disorder: a phase III, multicenter, randomized, double-blind, forced-dose, parallel-group study. Clin Ther 29:450-463

Biederman J, Mick E, Surman C, Doyle R, Hammerness P, Kotarski M, Spencer T (2010) A randomized, 3-phase, 34-week, doubleblind, long-term efficacy study of osmotic-release oral systemmethylphenidate in adults with attention-deficit/hyperactivity disorder. J Clin Psychopharmacol 30:549-553. doi:10.1097/JCP. 0b013e3181ee84a7

Bijlenga D, Van Someren EJ, Gruber R, Bron TI, Kruithof IF, Spanbroek EC, Kooij JJ (2013) Body temperature, activity and melatonin profiles in adults with attention-deficit/hyperactivity disorder and delayed sleep: a case-control study. J Sleep Res 22:607-616. doi:10.1111/jsr.12075

Block SL et al (2009) Once-daily atomoxetine for treating pediatric attention-deficit/hyperactivity disorder: comparison of morning and evening dosing. Clin Pediatr (Phila) 48:723-733. doi:10. 1177/0009922809335321

Boonstra AM, Kooij JJ, Oosterlaan J, Sergeant JA, Buitelaar JK, Van Someren EJ (2007) Hyperactive night and day? Actigraphy studies in adult ADHD: a baseline comparison and the effect of methylphenidate. Sleep 30:433-442

Bradley C (1937) The behavior of children receiving benzedrine. Am J Psychiatry 94:577-585

Breslau N, Roth T, Rosenthal L, Andreski P (1996) Sleep disturbance and psychiatric disorders: a longitudinal epidemiological study of young adults. Biol Psychiatry 39:411-418

Buysse DJ, Reynolds CF, Monk TH, Berman SR, Kupfer DJ (1989) The Pittsburgh Sleep Quality Index: a new instrument for psychiatric practice and research. Psychiatry Res 28:193-213

Carlson GA, Kelly KL (2003) Stimulant rebound: how common is it and what does it mean? J Child Adolesc Psychopharmacol 13:137-142. doi:10.1089/104454603322163853

Casas M et al (2013) Efficacy and safety of prolonged-release OROS methylphenidate in adults with attention deficit/hyperactivity disorder: a 13-week, randomized, double-blind, placebo-controlled, fixed-dose study. World J Biol Psychiatry 14:268-281. doi:10.3109/15622975.2011.600333

Chervin RD, Archbold KH, Dillon JE, Panahi P, Pituch KJ, Dahl RE, Guilleminault C (2002) Inattention, hyperactivity, and symptoms of sleep-disordered breathing. Pediatrics 109:449-456

Chervin RD et al (2006) Sleep-disordered breathing, behavior, and cognition in children before and after adenotonsillectomy. Pediatrics 117:e769-e778. doi:10.1542/peds.2005-1837

Chervin RD et al (2012) Esophageal pressures, polysomnography, and neurobehavioral outcomes of adenotonsillectomy in children. Chest 142:101-110. doi:10.1378/chest.11-2456

Chiang HL et al (2010) Association between symptoms and subtypes of attention-deficit hyperactivity disorder and sleep problems/disorders. J Sleep Res 19:535-545. doi:10.1111/j.1365-2869.2010.00832.x

Childress AC, Sallee FR (2012) Revisiting clonidine: an innovative add-on option for attention-deficit/hyperactivity disorder. Drugs Today (Barc) 48:207-217. doi:10.1358/dot.2012.48.3.1750904
Choi J, Yoon IY, Kim HW, Chung S, Yoo HJ (2010) Differences between objective and subjective sleep measures in children with attention deficit hyperactivity disorder. J Clin Sleep Med 6:589-595

Coghill D, Seth S (2006) Osmotic, controlled-release methylphenidate for the treatment of ADHD. Expert Opin Pharmacother 7:2119-2138. doi:10.1517/14656566.7.15.2119

Coghill D et al (2013) European, randomized, phase 3 study of lisdexamfetamine dimesylate in children and adolescents with attention-deficit/hyperactivity disorder. Eur Neuropsychopharmacol 12:1208-1218. doi:10.1016/j.euroneuro.2012. 11.012

Corkum P, Tannock R, Moldofsky H (1998) Sleep disturbances in children with attention-deficit/hyperactivity disorder. J Am Acad Child Adolesc Psychiatry 37:637-646. doi:10.1097/00004583199806000-00014

Corkum P, Moldofsky H, Hogg-Johnson S, Humphries T, Tannock R (1999) Sleep problems in children with attention-deficit/ hyperactivity disorder: impact of subtype, comorbidity, and stimulant medication. J Am Acad Child Adolesc Psychiatry 38:1285-1293. doi:10.1097/00004583-199910000-00018

Corkum P, Tannock R, Moldofsky H, Hogg-Johnson S, Humphries T (2001) Actigraphy and parental ratings of sleep in children with attention-deficit/hyperactivity disorder (ADHD). Sleep 24:303-312

Corkum P, Davidson F, Macpherson M (2011) A framework for the assessment and treatment of sleep problems in children with attention-deficit/hyperactivity disorder. Pediatr Clin North Am 58:667-683. doi:10.1016/j.pcl.2011.03.004

Cortese S, Vincenzi B (2012) Obesity and ADHD: clinical and neurobiological implications. Curr Top Behav Neurosci 9:199-218. doi:10.1007/7854_2011_154

Cortese S, Konofal E, Lecendreux M, Arnulf I, Mouren MC, Darra F, Dalla Bernardina B (2005) Restless legs syndrome and attentiondeficit/hyperactivity disorder: a review of the literature. Sleep 28:1007-1013

Cortese S, Konofal E, Yateman N, Mouren MC, Lecendreux M (2006a) Sleep and alertness in children with attention-deficit/ hyperactivity disorder: a systematic review of the literature. Sleep 29:504-511

Cortese S, Lecendreux M, Mouren MC, Konofal E (2006b) ADHD and insomnia. J Am Acad Child Adolesc Psychiatry 45:384-385. doi:10.1097/01.chi.0000199577.12145.bc

Cortese S et al (2007) Parent reports of sleep/alertness problems and ADHD symptoms in a sample of obese adolescents. J Psychosom Res 63:587-590. doi:10.1016/j.jpsychores.2007.08.005

Cortese S et al (2008a) Attention-deficit/hyperactivity disorder (ADHD) and obesity: a systematic review of the literature. Crit Rev Food Sci Nutr 48:524-537. doi:10.1080/104083907015 40124

Cortese S, Konofal E, Dalla Bernardina B, Mouren MC, Lecendreux M (2008b) Does excessive daytime sleepiness contribute to explaining the association between obesity and ADHD symptoms? Med Hypotheses 70:12-16. doi:10.1016/j.mehy.2007.04. 036

Cortese S, Faraone SV, Konofal E, Lecendreux M (2009) Sleep in children with attention-deficit/hyperactivity disorder: meta-analysis of subjective and objective studies. J Am Acad Child Adolesc Psychiatry 48:894-908. doi:10.1097/CHI.0b013e3181 ac09c9

Cortese S, Angriman M, Lecendreux M, Konofal E (2012) Iron and attention deficit/hyperactivity disorder: what is the empirical evidence so far? A systematic review of the literature. Expert Rev Neurother 12:1227-1240. doi:10.1586/ern.12.116

Cortese S et al (2013a) Assessment and management of sleep problems in youths with attention-deficit/hyperactivity disorder. 
J Am Acad Child Adolesc Psychiatry 52:784-796. doi:10.1016/j. jaac.2013.06.001

Cortese S et al (2013b) Practitioner review: current best practice in the management of adverse events during treatment with ADHD medications in children and adolescents. J Child Psychol Psychiatry 54:227-246. doi:10.1111/jcpp.12036

Cortese S, Ramos Olazagasti MA, Klein RG, Castellanos FX, Proal E, Mannuzza S (2013c) Obesity in men with childhood ADHD: a 33-year controlled, prospective, follow-up study. Pediatrics 131:e1731-e1738. doi:10.1542/peds.2012-0540

De Crescenzo F et al (2014) The use of actigraphy in the monitoring of methylphenidate versus placebo in ADHD: a meta-analysis. Atten Defic Hyperact Disord 6:49-58. doi:10.1007/s12402-013-0122-x

Dittmann RW et al (2013) Efficacy and safety of lisdexamfetamine dimesylate and atomoxetine in the treatment of attention-deficit/ hyperactivity disorder: a head-to-head, randomized, doubleblind, phase IIIb study. CNS Drugs 27:1081-1092. doi:10.1007/ s40263-013-0104-8

Efron D, Jarman F, Barker M (1997) Side effects of methylphenidate and dexamphetamine in children with attention deficit hyperactivity disorder: a double-blind, crossover trial. Pediatrics 100:662-666

Efron D, Lycett K, Sciberras E (2014) Use of sleep medication in children with ADHD. Sleep Med 15:472-475. doi:10.1016/j. sleep.2013.10.018

England SJ et al (2011) L-dopa improves restless legs syndrome and periodic limb movements in sleep but not attention-deficithyperactivity disorder in a double-blind trial in children. Sleep Med 12:471-477. doi:10.1016/j.sleep.2011.01.008

Faraone SV, McBurnett K, Sallee FR, Steeber J, Lopez FA (2013) Guanfacine extended release: a novel treatment for attentiondeficit/hyperactivity disorder in children and adolescents. Clin Ther 35:1778-1793. doi:10.1016/j.clinthera.2013.09.005

Ferri R, Bruni O, Novelli L, Picchietti MA, Picchietti DL (2013) Time structure of leg movement activity during sleep in attention-deficit/hyperactivity disorder and effects of levodopa. Sleep Med 14:359-366. doi:10.1016/j.sleep.2012.12.012

Findling RL, Bukstein OG, Melmed RD, Lopez FA, Sallee FR, Arnold LE, Pratt RD (2008) A randomized, double-blind, placebo-controlled, parallel-group study of methylphenidate transdermal system in pediatric patients with attention-deficit/ hyperactivity disorder. J Clin Psychiatry 69:149-159

Findling RL, Childress AC, Cutler AJ, Gasior M, Hamdani M, Ferreira-Cornwell MC, Squires L (2011) Efficacy and safety of lisdexamfetamine dimesylate in adolescents with attentiondeficit/hyperactivity disorder. J Am Acad Child Adolesc Psychiatry 50:395-405. doi:10.1016/j.jaac.2011.01.007

Fisher BE, Pauley C, McGuire K (1989) Children's Sleep Behavior Scale: normative data on 870 children in grades 1 to 6 . Percept Mot Skills 68:227-236

Galland BC, Tripp EG, Taylor BJ (2010) The sleep of children with attention deficit hyperactivity disorder on and off methylphenidate: a matched case-control study. J Sleep Res 19:366-373. doi:10.1111/j.1365-2869.2009.00795.x

Gamble KL, May RS, Besing RC, Tankersly AP, Fargason RE (2013) Delayed sleep timing and symptoms in adults with attention-deficit/hyperactivity disorder: a controlled actigraphy study. Chronobiol Int 30:598-606. doi:10.3109/07420528.2012. 754454

Garnock-Jones KP, Keating GM (2009) Atomoxetine: a review of its use in attention-deficit hyperactivity disorder in children and adolescents. Paediatr Drugs 11:203-226. doi:10.2165/00148581200911030-00005

Giblin JM, Strobel AL (2011) Effect of lisdexamfetamine dimesylate on sleep in children with ADHD. J Atten Disord 15:491-498. doi: $10.1177 / 1087054710371195$
Golan N, Shahar E, Ravid S, Pillar G (2004) Sleep disorders and daytime sleepiness in children with attention-deficit/hyperactive disorder. Sleep 27:261-266

Gomes AA, Parchao C, Almeida A, Clemente V, Pinto de Azevedo MH (2013) Sleep-wake patterns reported by parents in hyperactive children diagnosed according to ICD-10, as compared to paired controls. Child Psychiatry Hum Dev. doi:10.1007/s10578013-0422-6

Gottlieb DJ et al (2003) Symptoms of sleep-disordered breathing in 5 -year-old children are associated with sleepiness and problem behaviors. Pediatrics 112:870-877

Gozal D (1998) Sleep-disordered breathing and school performance in children. Pediatrics 102:616-620

Gradisar M, Gardner G, Dohnt H (2011) Recent worldwide sleep patterns and problems during adolescence: a review and metaanalysis of age, region, and sleep. Sleep Med 12:110-118. doi:10.1016/j.sleep.2010.11.008

Graham $\mathbf{J}$ et al (2011) European guidelines on managing adverse effects of medication for ADHD. Eur Child Adolesc Psychiatry 20:17-37. doi:10.1007/s00787-010-0140-6

Greenhill L, Puig-Antich J, Goetz R, Hanlon C, Davies M (1983) Sleep architecture and REM sleep measures in prepubertal children with attention deficit disorder with hyperactivity. Sleep 6:91-101

Gruber R (2009) Sleep characteristics of children and adolescents with attention deficit-hyperactivity disorder. Child Adolesc Psychiatr Clin N Am 18:863-876. doi:10.1016/j.chc.2009.04. 011

Gruber R (2014) ADHD, anxiety and sleep: a window to understanding the interplay between sleep, emotional regulation and attention in children? Behav Sleep Med 12:84-87. doi:10. 1080/15402002.2014.862089

Gruber R, Sadeh A (2004) Sleep and neurobehavioral functioning in boys with attention-deficit/hyperactivity disorder and no reported breathing problems. Sleep 27:267-273

Gruber R, Sadeh A, Raviv A (2000) Instability of sleep patterns in children with attention-deficit/hyperactivity disorder. J Am Acad Child Adolesc Psychiatry 39:495-501. doi:10.1097/00004583200004000-00019

Gruber R, Xi T, Frenette S, Robert M, Vannasinh P, Carrier J (2009) Sleep disturbances in prepubertal children with attention deficit hyperactivity disorder: a home polysomnography study. Sleep 32:343-350

Gruber R, Wiebe S, Montecalvo L, Brunetti B, Amsel R, Carrier J (2011) Impact of sleep restriction on neurobehavioral functioning of children with attention deficit hyperactivity disorder. Sleep 34:315-323

Gruber R, Fontil L, Bergmame L, Wiebe ST, Amsel R, Frenette S, Carrier J (2012a) Contributions of circadian tendencies and behavioral problems to sleep onset problems of children with ADHD. BMC Psychiatry 12:212. doi:10.1186/1471-244x-12212

Gruber R, Michaelsen S, Bergmame L, Frenette S, Bruni O, Fontil L, Carrier J (2012b) Short sleep duration is associated with teacherreported inattention and cognitive problems in healthy schoolaged children. Nat Sci Sleep 4:33-40. doi:10.2147/NSS.S24607

Hansen BH, Skirbekk B, Oerbeck B, Wentzel-Larsen T, Kristensen H (2013) Associations between sleep problems and attentional and behavioral functioning in children with anxiety disorders and ADHD. Behav Sleep Med 12:53-68. doi:10.1080/15402002. 2013.764525

Hart CN, Larose JG, Fava JL, James BL, Wing RR (2013) The association between time in bed and obesity risk in young adults. Behav Sleep Med 11:321-327. doi:10.1080/15402002.2012.700289

Hodgkins P, Shaw M, Coghill D, Hechtman L (2012) Amfetamine and methylphenidate medications for attention-deficit/hyperactivity 
disorder: complementary treatment options. Eur Child Adolesc Psychiatry 21:477-492. doi:10.1007/s00787-012-0286-5

Hodgkins P et al (2013) Management of ADHD in children across Europe: patient demographics, physician characteristics and treatment patterns. Eur J Pediatr 172:895-906. doi:10.1007/ s00431-013-1969-8

Huang YS, Guilleminault C, Li HY, Yang CM, Wu YY, Chen NH (2007) Attention-deficit/hyperactivity disorder with obstructive sleep apnea: a treatment outcome study. Sleep Med 8:18-30. doi:10.1016/j.sleep.2006.05.016

Hvolby A, Bilenberg N (2011) Use of ball blanket in attention-deficit/ hyperactivity disorder sleeping problems. Nord J Psychiatry 65:89-94. doi:10.3109/08039488.2010.501868

Hvolby A, Jorgensen J, Bilenberg N (2008) Actigraphic and parental reports of sleep difficulties in children with attention-deficit/ hyperactivity disorder. Arch Pediatr Adolesc Med 162:323-329. doi:10.1001/archpedi.162.4.323

Hvolby A, Jorgensen J, Bilenberg N (2009) Parental rating of sleep in children with attention deficit/hyperactivity disorder. Eur Child Adolesc Psychiatry 18:429-438. doi:10.1007/s00787-009-0750-z

Ironside S, Davidson F, Corkum P (2010) Circadian motor activity affected by stimulant medication in children with attentiondeficit/hyperactivity disorder. J Sleep Res 19:546-551. doi:10. 1111/j.1365-2869.2010.00845.x

Ivanenko A, Crabtree VM, Gozal D (2004) Sleep in children with psychiatric disorders. Pediatr Clin North Am 51:51-68

Jerome L (2001) Can methylphenidate facilitate sleep in children with attention deficit hyperactivity disorder? J Child Adolesc Psychopharmacol 11:109. doi:10.1089/104454601750143564

Katz ES, Greene MG, Carson KA, Galster P, Loughlin GM, Carroll J, Marcus CL (2002) Night-to-night variability of polysomnography in children with suspected obstructive sleep apnea. J Pediatr 140:589-594. doi:10.1067/mpd.2002.123290

Kim HW et al (2010) The effect of OROS methylphenidate on the sleep of children with attention-deficit/hyperactivity disorder. Int Clin Psychopharmacol 25:107-115. doi:10.1097/YIC.0b013e3283364411

Kinsbourne M (1973) Stimulants for insomnia. N Engl J Med 288:1129. doi:10.1056/NEJM197305242882121

Kirov R, Brand S (2014) Sleep problems and their effect in ADHD. Expert Rev Neurother 14:287-299. doi:10.1586/14737175.2014. 885382

Kirov R, Pillar G, Rothenberger A (2004) REM-sleep changes in children with attention-deficit/hyperactivity disorder: methodologic and neurobiologic considerations. Sleep 27:1215

Kirov R, Uebel H, Albrecht B, Banaschewski T, Yordanova J, Rothenberger A (2012) Attention-deficit/hyperactivity disorder (ADHD) and adaptation night as determinants of sleep patterns in children. Eur Child Adolesc Psychiatry 21:681-690. doi:10. 1007/s00787-012-0308-3

Kollins SH et al (2011) Psychomotor functioning and alertness with guanfacine extended release in subjects with attention-deficit/ hyperactivity disorder. J Child Adolesc Psychopharmacol 21:111-120. doi:10.1089/cap.2010.0064

Konofal E et al (2008) Effects of iron supplementation on attention deficit hyperactivity disorder in children. Pediatr Neurol 38:20-26. doi:10.1016/j.pediatrneurol.2007.08.014

Kooij JJ, Middelkoop HA, van Gils K, Buitelaar JK (2001) The effect of stimulants on nocturnal motor activity and sleep quality in adults with ADHD: an open-label case-control study. J Clin Psychiatry 62:952-956

Kratochvil CJ, Lake M, Pliszka SR, Walkup JT (2005) Pharmacological management of treatment-induced insomnia in ADHD. J Am Acad Child Adolesc Psychiatry 44:499-501. doi:10.1097/ 01.chi.0000155322.32500.3a

Lakhan SE, Kirchgessner A (2012) Prescription stimulants in individuals with and without attention deficit hyperactivity disorder: misuse, cognitive impact, and adverse effects. Brain Behav 2:661-677. doi:10.1002/brb3.78

Lal C, Strange C, Bachman D (2012) Neurocognitive impairment in obstructive sleep apnea. Chest 141:1601-1610. doi:10.1378/ chest.11-2214

LeBourgeois MK, Avis K, Mixon M, Olmi J, Harsh J (2004) Snoring, sleep quality, and sleepiness across attention-deficit/hyperactivity disorder subtypes. Sleep 27:520-525

Lecendreux M, Cortese S (2007) Sleep problems associated with ADHD: a review of current therapeutic options and recommendations for the future. Expert Rev Neurother 7:1799-1806. doi:10.1586/14737175.7.12.1799

Lecendreux M, Konofal E, Bouvard M, Falissard B, Mouren-Simeoni MC (2000) Sleep and alertness in children with ADHD. J Child Psychol Psychiatry 41:803-812

Lee SH et al (2012) Effect of methylphenidate on sleep parameters in children with ADHD. Psychiatry Investig 9:384-390. doi:10. 4306/pi.2012.9.4.384

Lim CG, Ooi YP, Fung DS, Mahendran R, Kaur A (2008) Sleep disturbances in Singaporean children with attention deficit hyperactivity disorder. Ann Acad Med Singap 37:655-661

Lorenzo JL, Barbanoj MJ (2002) Variability of sleep parameters across multiple laboratory sessions in healthy young subjects: the "very first night effect". Psychophysiology 39:409-413. doi:10. 1017/s0048577202394010

Mayes SD et al (2009) ADHD subtypes and comorbid anxiety, depression, and oppositional-defiant disorder: differences in sleep problems. J Pediatr Psychol 34:328-337. doi:10.1093/jpepsy/jsn083

Medori R et al (2008) A randomized, placebo-controlled trial of three fixed dosages of prolonged-release OROS methylphenidate in adults with attention-deficit/hyperactivity disorder. Biol Psychiatry 63:981-989. doi:10.1016/j.biopsych.2007.11.008

Meltzer LJ, Montgomery-Downs HE, Insana SP, Walsh CM (2012) Use of actigraphy for assessment in pediatric sleep research. Sleep Med Rev 16:463-475. doi:10.1016/j.smrv.2011.10.002

Miano S et al (2006) NREM sleep instability is reduced in children with attention-deficit/hyperactivity disorder. Sleep 29:797-803

Miano S et al (2013) Case reports of sleep phenotypes of ADHD: from hypothesis to clinical practice. J Atten Disord 17:565-573. doi:10.1177/1087054713497254

Mick E, Biederman J, Jetton J, Faraone SV (2000) Sleep disturbances associated with attention deficit hyperactivity disorder: the impact of psychiatric comorbidity and pharmacotherapy. J Child Adolesc Psychopharmacol 10:223-231. doi:10.1089/10445460050167331

Mindell JA, Kuhn B, Lewin DS, Meltzer LJ, Sadeh A (2006) Behavioral treatment of bedtime problems and night wakings in infants and young children. Sleep 29:1263-1276

Moreau V, Rouleau N, Morin CM (2013) Sleep of children with attention deficit hyperactivity disorder: actigraphic and parental reports. Behav Sleep Med 12:69-83. doi:10.1080/15402002. 2013.764526

Morgenthaler TI et al (2007) Practice parameters for the treatment of narcolepsy and other hypersomnias of central origin. Sleep 30:1705-1711

Mullin BC, Harvey AG, Hinshaw SP (2011) A preliminary study of sleep in adolescents with bipolar disorder, ADHD, and nonpatient controls. Bipolar Disord 13:425-432. doi:10.1111/j.13995618.2011.00933.x

Newcorn JH, Kratochvil CJ, Allen AJ, Casat CD, Ruff DD, Moore RJ, Michelson D (2008) Atomoxetine and osmotically released methylphenidate for the treatment of attention deficit hyperactivity disorder: acute comparison and differential response. Am J Psychiatry 165:721-730. doi:10.1176/appi.ajp.2007.05091676

Nutt DJ et al (2007) Evidence-based guidelines for management of attention-deficit/hyperactivity disorder in adolescents in transition to adult services and in adults: recommendations from the 
British Association for Psychopharmacology. J Psychopharmacol (Oxford, England) 21:10-41. doi:10.1177/0269881106073219

O'Brien LM (2009) The neurocognitive effects of sleep disruption in children and adolescents. Child Adolesc Psychiatr Clin N Am 18:813-823. doi:10.1016/j.chc.2009.04.008

O'Brien LM, Ivanenko A, Crabtree VM, Holbrook CR, Bruner JL, Klaus CJ, Gozal D (2003a) The effect of stimulants on sleep characteristics in children with attention deficit/hyperactivity disorder. Sleep Med 4:309-316

O'Brien LM, Ivanenko A, Crabtree VM, Holbrook CR, Bruner JL, Klaus CJ, Gozal D (2003b) Sleep disturbances in children with attention deficit hyperactivity disorder. Pediatr Res 54:237-243. doi:10.1203/01.PDR.0000072333.11711.9A

Owens JA (2005) The ADHD and sleep conundrum: a review. J Dev Behav Pediatr 26:312-322

Owens JA (2008) Sleep disorders and attention-deficit/hyperactivity disorder. Curr Psychiatry Rep 10:439-444

Owens JA, Dalzell V (2005) Use of the 'BEARS' sleep screening tool in a pediatric residents' continuity clinic: a pilot study. Sleep Med 6:63-69. doi:10.1016/j.sleep.2004.07.015

Owens JA, Spirito A, McGuinn M (2000) The Children's Sleep Habits Questionnaire (CSHQ): psychometric properties of a survey instrument for school-aged children. Sleep 23:1043-1051

Owens J, Sangal RB, Sutton VK, Bakken R, Allen AJ, Kelsey D (2009) Subjective and objective measures of sleep in children with attention-deficit/hyperactivity disorder. Sleep Med 10:446-456. doi:10.1016/j.sleep.2008.03.013

Owens $\mathrm{J}$ et al (2013) Future research directions in sleep and ADHD: report of a consensus working group. J Atten Disord 17:550-564. doi:10.1177/1087054712457992

Paavonen EJ et al (2009) Short sleep duration and behavioral symptoms of attention-deficit/hyperactivity disorder in healthy 7- to 8-year-old children. Pediatrics 123:e857-e864. doi:10. 1542/peds.2008-2164

Pesonen AK et al (2010) Sleep duration and regularity are associated with behavioral problems in 8-year-old children. Int J Behav Med 17:298-305. doi:10.1007/s12529-009-9065-1

Philipsen A et al (2005) Sleep in adults with attention-deficit/ hyperactivity disorder: a controlled polysomnographic study including spectral analysis of the sleep EEG. Sleep 28:877-884

Picchietti MA, Picchietti DL (2010) Advances in pediatric restless legs syndrome: iron, genetics, diagnosis and treatment. Sleep Med 11:643-651. doi:10.1016/j.sleep.2009.11.014

Picchietti D, Allen RP, Walters AS, Davidson JE, Myers A, FeriniStrambi L (2007) Restless legs syndrome: prevalence and impact in children and adolescents - the Peds REST study. Pediatrics 120:253-266. doi:10.1542/peds.2006-2767

Picchietti DL, Bruni O, de Weerd A, Durmer JS, Kotagal S, Owens JA, Simakajornboon N (2013) Pediatric restless legs syndrome diagnostic criteria: an update by the International Restless Legs Syndrome Study Group. Sleep Med 14:1253-1259. doi:10.1016/ j.sleep.2013.08.778

Polanczyk G, de Lima MS, Horta BL, Biederman J, Rohde LA (2007) The worldwide prevalence of ADHD: a systematic review and metaregression analysis. Am J Psychiatry 164:942-948. doi:10. 1176/appi.ajp.164.6.942

Prihodova I, Paclt I, Kemlink D, Skibova J, Ptacek R, Nevsimalova S (2010) Sleep disorders and daytime sleepiness in children with attention-deficit/hyperactivity disorder: a two-night polysomnographic study with a multiple sleep latency test. Sleep Med 11:922-928. doi:10.1016/j.sleep.2010.03.017

Prihodova I, Paclt I, Kemlink D, Nevsimalova S (2012) Sleep microstructure is not altered in children with attention-deficit/ hyperactivity disorder (ADHD). Physiol Res/Academia Scientiarum Bohemoslovaca 61:125-133
Prince JB, Wilens TE, Biederman J, Spencer TJ, Wozniak JR (1996) Clonidine for sleep disturbances associated with attention-deficit hyperactivity disorder: a systematic chart review of 62 cases. J Am Acad Child Adolesc Psychiatry 35:599-605. doi:10.1097/ 00004583-199605000-00014

Rosen CL, Storfer-Isser A, Taylor HG, Kirchner HL, Emancipator JL, Redline S (2004) Increased behavioral morbidity in school-aged children with sleep-disordered breathing. Pediatrics 114:1640-1648. doi:10.1542/peds.2004-0103

Rowland AS, Lesesne CA, Abramowitz AJ (2002) The epidemiology of attention-deficit/hyperactivity disorder (ADHD): a public health view. Ment Retard Dev Disabil Res Rev 8:162-170. doi: $10.1002 / \operatorname{mrdd} .10036$

Sadeh A, Pergamin L, Bar-Haim Y (2006) Sleep in children with attention-deficit hyperactivity disorder: a meta-analysis of polysomnographic studies. Sleep Med Rev 10:381-398. doi:10.1016/ j.smrv.2006.03.004

Sangal RB, Owens J, Allen AJ, Sutton V, Schuh K, Kelsey D (2006) Effects of atomoxetine and methylphenidate on sleep in children with ADHD. Sleep 29:1573-1585

Saxby H, Morgan H (1993) Behaviour problems in children with learning disabilities: to what extent do they exist and are they a problem? Child Care Health Dev 19:149-157

Scholle S, Scholle HC, Kemper A, Glaser S, Rieger B, Kemper G, Zwacka G (2003) First night effect in children and adolescents undergoing polysomnography for sleep-disordered breathing. Clin Neurophysiol 114:2138-2145

Sciberras E, Efron D, Gerner B, Davey M, Mensah F, Oberklaid F, Hiscock H (2010) Study protocol: the sleeping sound with attention-deficit/hyperactivity disorder project. BMC Pediatr 10:101. doi:10.1186/1471-2431-10-101

Sciberras E, Fulton M, Efron D, Oberklaid F, Hiscock H (2011) Managing sleep problems in school aged children with ADHD: a pilot randomised controlled trial. Sleep Med 12:932-935. doi:10. 1016/j.sleep.2011.02.006

Scott N, Blair PS, Emond AM, Fleming PJ, Humphreys JS, Henderson J, Gringras P (2013) Sleep patterns in children with ADHD: a population-based cohort study from birth to 11 years. J Sleep Res 22:121-128. doi:10.1111/j.1365-2869.2012.01054.x

Setyawan J, Guerin A, Hodgkins P, Gauthier G, Cloutier M, Wu E, Haim Erder M (2013a) Treatment persistence in attention deficit/ hyperactivity disorder: a retrospective analysis of patients initiated on lisdexamfetamine versus other medications. J Med Econ 16:1275-1289. doi:10.3111/13696998.2013.839947

Setyawan J, Hodgkins P, Guerin A, Gauthier G, Cloutier M, Wu EQ, Erder MH (2013b) Comparing treatment adherence of lisdexamfetamine and other medications for the treatment of attention deficit/hyperactivity disorder: a retrospective analysis. J Med Econ 16:962-975. doi:10.3111/13696998.2013.800524

Silvestri R et al (2009) Sleep disorders in children with attentiondeficit/hyperactivity disorder (ADHD) recorded overnight by video-polysomnography. Sleep Med 10:1132-1138. doi:10. 1016/j.sleep.2009.04.003

Sobanski E, Schredl M, Kettler N, Alm B (2008) Sleep in adults with attention deficit hyperactivity disorder (ADHD) before and during treatment with methylphenidate: a controlled polysomnographic study. Sleep 31:375-381

Soylu E, Soylu N, Yildirim YS, Sakallioglu O, Polat C, Orhan I (2013) Psychiatric disorders and symptoms severity in patients with adenotonsillar hypertrophy before and after adenotonsillectomy. Int J Pediatr Otorhinolaryngol 77:1775-1781. doi:10. 1016/j.ijporl.2013.08.020

Spencer T, Biederman J, Wilens TE, Faraone SV (1998) Adults with attention-deficit/hyperactivity disorder: a controversial diagnosis. J Clin Psychiatry 59(Suppl 7):59-68 
Spencer SV, Hawk LW Jr, Richards JB, Shiels K, Pelham WE Jr, Waxmonsky JG (2009) Stimulant treatment reduces lapses in attention among children with ADHD: the effects of methylphenidate on intra-individual response time distributions. J Abnorm Child Psychol 37:805-816. doi:10.1007/s10802-009-9316-2

Spruyt K, Gozal D (2011) Sleep disturbances in children with attention-deficit/hyperactivity disorder. Expert Rev Neurother 11:565-577. doi:10.1586/ern.11.7

Spruyt K, Gozal D, Dayyat E, Roman A, Molfese DL (2011) Sleep assessments in healthy school-aged children using actigraphy: concordance with polysomnography. J Sleep Res 20:223-232. doi:10.1111/j.1365-2869.2010.00857.x

Steer C, Froelich J, Soutullo CA, Johnson M, Shaw M (2012) Lisdexamfetamine dimesylate: a new therapeutic option for attention-deficit hyperactivity disorder. CNS Drugs 26:691-705. doi:10.2165/11634340-000000000-00000

Stein MA (1999) Unravelling sleep problems in treated and untreated children with ADHD. J Child Adolesc Psychopharmacol 9:157-168

Stein MA, Waldman ID, Charney E, Aryal S, Sable C, Gruber R, Newcorn JH (2011) Dose effects and comparative effectiveness of extended release dexmethylphenidate and mixed amphetamine salts. J Child Adolesc Psychopharmacol 21:581-588. doi:10.1089/cap.2011.0018

Sung V, Hiscock H, Sciberras E, Efron D (2008) Sleep problems in children with attention-deficit/hyperactivity disorder: prevalence and the effect on the child and family. Arch Pediatr Adolesc Med 162:336-342. doi:10.1001/archpedi.162.4.336

Suratt PM, Diamond R, Barth JT, Nikova M, Rembold C (2011) Movements during sleep correlate with impaired attention and verbal and memory skills in children with adenotonsillar hypertrophy suspected of having obstructive sleep disordered breathing. Sleep Med 12:322-328. doi:10.1016/j.sleep.2010.10. 007

Surman CB, Roth T (2011) Impact of stimulant pharmacotherapy on sleep quality: post hoc analyses of 2 large, double-blind, randomized, placebo-controlled trials. J Clin Psychiatry 72:903-908. doi:10.4088/JCP.11m06838

Swanson J et al (2003) Development of a new once-a-day formulation of methylphenidate for the treatment of attention-deficit/ hyperactivity disorder: proof-of-concept and proof-of-product studies. Arch Gen Psychiatry 60:204-211

Taheri S, Lin L, Austin D, Young T, Mignot E (2004) Short sleep duration is associated with reduced leptin, elevated ghrelin, and increased body mass index. PLoS Med 1:e62. doi:10.1371/ journal.pmed.0010062

Tamm L, Narad ME, Antonini TN, O’Brien KM, Hawk LW Jr, Epstein JN (2012) Reaction time variability in ADHD: a review. Neurotherapeutics 9:500-508. doi:10.1007/s13311-012-0138-5

Tjon Pian Gi CV, Broeren JP, Starreveld JS, Versteegh FG (2003) Melatonin for treatment of sleeping disorders in children with attention deficit/hyperactivity disorder: a preliminary open label study. Eur J Pediatr 162:554-555. doi:10.1007/s00431-003$1207-x$

Tsai MH, Huang YS (2010) Attention-deficit/hyperactivity disorder and sleep disorders in children. Med Clin North Am 94:615-632. doi:10.1016/j.mena.2010.03.008
Van der Heijden KB, Smits MG, Van Someren EJ, Gunning WB (2005) Idiopathic chronic sleep onset insomnia in attentiondeficit/hyperactivity disorder: a circadian rhythm sleep disorder. Chronobiol Int 22:559-570. doi:10.1081/cbi-200062410

Van der Heijden KB, Smits MG, Van Someren EJ, Ridderinkhof KR, Gunning WB (2007) Effect of melatonin on sleep, behavior, and cognition in ADHD and chronic sleep-onset insomnia. J Am Acad Child Adolesc Psychiatry 46:233-241. doi:10.1097/01.chi. 0000246055.76167.0d

Van Veen MM, Kooij JJ, Boonstra AM, Gordijn MC, Van Someren EJ (2010) Delayed circadian rhythm in adults with attentiondeficit/hyperactivity disorder and chronic sleep-onset insomnia. Biol Psychiatry 67:1091-1096. doi:10.1016/j.biopsych.2009.12. 032

Vriend J, Corkum P (2011) Clinical management of behavioral insomnia of childhood. Psychol Res Behav Manag 4:69-79. doi:10.2147/PRBM.S14057

Weiss MD, Wasdell MB, Bomben MM, Rea KJ, Freeman RD (2006) Sleep hygiene and melatonin treatment for children and adolescents with ADHD and initial insomnia. J Am Acad Child Adolesc Psychiatry 45:512-519. doi:10.1097/01chi.0000205706. 78818.ef

Wender PH (1998) Attention-deficit hyperactivity disorder in adults. Psychiatr Clin North Am 21:761-774

Wiebe S, Carrier J, Frenette S, Gruber R (2013) Sleep and sleepiness in children with attention deficit/hyperactivity disorder and controls. J Sleep Res 22:41-49. doi:10.1111/j.1365-2869.2012. 01033. $\mathrm{x}$

Wiggs L, Montgomery P, Stores G (2005) Actigraphic and parent reports of sleep patterns and sleep disorders in children with subtypes of attention-deficit hyperactivity disorder. Sleep 28:1437-1445

Wilens TE, Biederman J, Spencer T (1994) Clonidine for sleep disturbances associated with attention-deficit hyperactivity disorder. J Am Acad Child Adolesc Psychiatry 33:424-426

Wilens $\mathrm{T}$ et al (2003) ADHD treatment with once-daily OROS methylphenidate: interim 12-month results from a long-term open-label study. J Am Acad Child Adolesc Psychiatry 42:424-433. doi:10.1097/01.CHI.0000046814.95464.7D

Wolraich ML et al (2001) Randomized, controlled trial of OROS methylphenidate once a day in children with attention-deficit/ hyperactivity disorder. Pediatrics 108:883-892

Wolraich $\mathrm{M}$ et al (2011) ADHD: clinical practice guideline for the diagnosis, evaluation, and treatment of attention-deficit/hyperactivity disorder in children and adolescents. Pediatrics 128:1007-1022. doi:10.1542/peds.2011-2654

World Health Organization (1992) International statistical classification of diseases and related health problems (ICD-10), 10th edn. World Health Organization, Geneva

Yoon SY, Jain U, Shapiro C (2012) Sleep in attention-deficit/ hyperactivity disorder in children and adults: past, present, and future. Sleep Med Rev 16:371-388. doi:10.1016/j.smrv.2011.07. 001

Youssef NA, Ege M, Angly SS, Strauss JL, Marx CE (2011) Is obstructive sleep apnea associated with ADHD? Ann Clin Psychiatry 23:213-224 